\title{
MÉTODO Y CRITERIOS EN LA RESTAURACIÓN DEL PALAU GÜELL DE BARCELONA (ESPAÑA)
}

\author{
(METHODS AND CRITERIA IN THE RESTORATION OF THE PALAU GÜELL IN \\ BARCELONA, SPAIN)
}

\author{
Antoni González Moreno-Navarro, arquitecto \\ Jefe del Servicio del Patrimonio Arquitectónico de la Diputación de Barcelona.
}

Fecha de recepción: 1 - XII- 93

\begin{abstract}
RESUMEN
Entre 1986 y 1992 se restauraron las fachadas y la azotea, se renovaron las instalaciones $y$ se remozaron el zaguán y la conserjería para acoger a los visitantes, principales destinatarios del edificio. Los estudios paralelos, referidos tanto a aspectos históricos como arquitectónicos $y$ constructivos, se han reflejado en un atlas histórico-constructivo.

La obra se enfocó con eclecticismo y elasticidad. En unos episodios se optó por la reconstrucción mimética; en otros, después de un análisis crítico, se planteó una recuperación analógica o la diacronía armónica. De esta manera se actuó en la azotea, singular mezcla de terraza de servicio doméstico y de museo de escultura al aire libre.
\end{abstract}

Algunas chimeneas de ladrillo visto o revestidas fueron reconstruidas fielmente. De las caperuzas desnudas se decidió recuperar el revestimiento y se confió su diseño a diversos artistas, no para que imitaran a Gaudi, sino para que aportaran su creatividad. El paisaje de chimeneas recuperaría así una parte esencial de su autenticidad: la textura, el color.

\section{SUMMARY}

Between 1986 and 1992 the façade and the roof were restored, the installations were renewed and the vestibule and the reception were renovated in order to welcome the visitors, the principal users of the building. The parallel studies dealing both with the historical aspect and the architectural and construction ones are reflected in a historical-constructive atlas.

The work was approached wich eclecticism and elasticity. In some cases, the mimetic reconstruction was chosen; in others, after a critical analysis, an analogical restoration or the harmonious diachrony was opted for. This was the solution chosen for the roof, a peculiar combination of a terrace for domestic service use and an open-air sculpture museum.

Some chimneys of uncovered brick as covered ones were faithfully restored. It was decided to retrieve the coating of the bare cowls. Various artists were entrusted with this work with the purpose of contributing their creativity rather than imitate Gaudi. In that way, the chimenney landscape recovered its authenticity: the texture, the colour.
En su apasionado libro sobre la ciudad de Barcelona, el crítico australiano Robert Hughes trata la obra de Gaudí de "alternativamente mística, penitencial y violentamente exaltada, estructuralmente atrevida y llena de metáforas, obsesionada con su papel como espejo del mundo" ${ }^{1}$. Es sorprendente, pero no insólito, que incluso el agudo crítico de Time haya caído en la trampa que, paradójicamente, la crítica culta pretende deshacer: la maraña trenzada por los hagiógrafos de Gaudí.

La obra de Antoni Gaudí es, antes que nada -o casi únicamente-, arquitectura. Sus atractivas formas y sugestivos espacios no tienen en las referencias simbólicas o íntimas ni su origen ni su fin. Nacen de una manera personal e innovadora de concebir la arquitectura y se supeditan al lugar, al entorno, al momento, al usuario. El Palau Güell de Barcelona, a pesar de ser una obra de juventud (cuando recibió el encargo de Eusebio Güell, Gaudí tenía 33 años), es una buena prueba de todo ello. En su concepción y diseño el arquitecto introdujo ya el que sería el repertorio formal, espacial y constructivo que ha merecido el reconocimiento universal de su autor. 


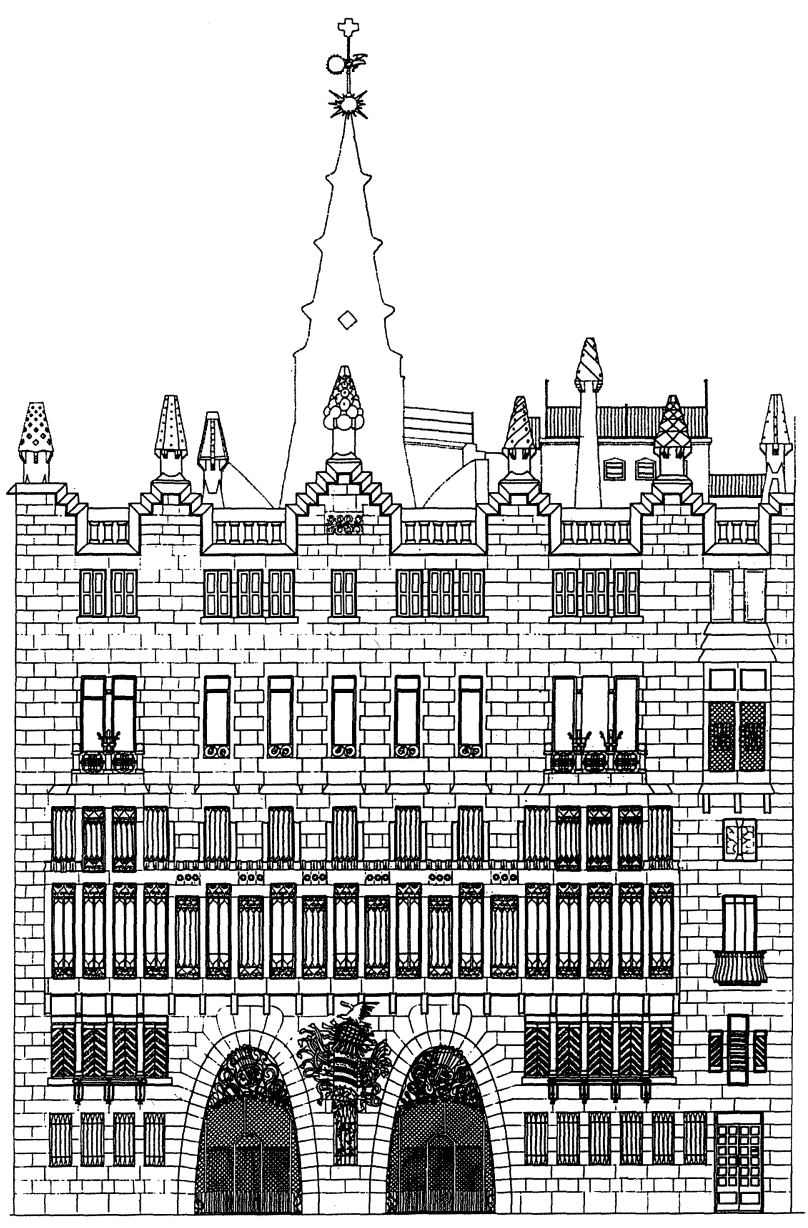

Fachada a la calle Nou de la Rambla. Dibujos: Txetxu Sanz.

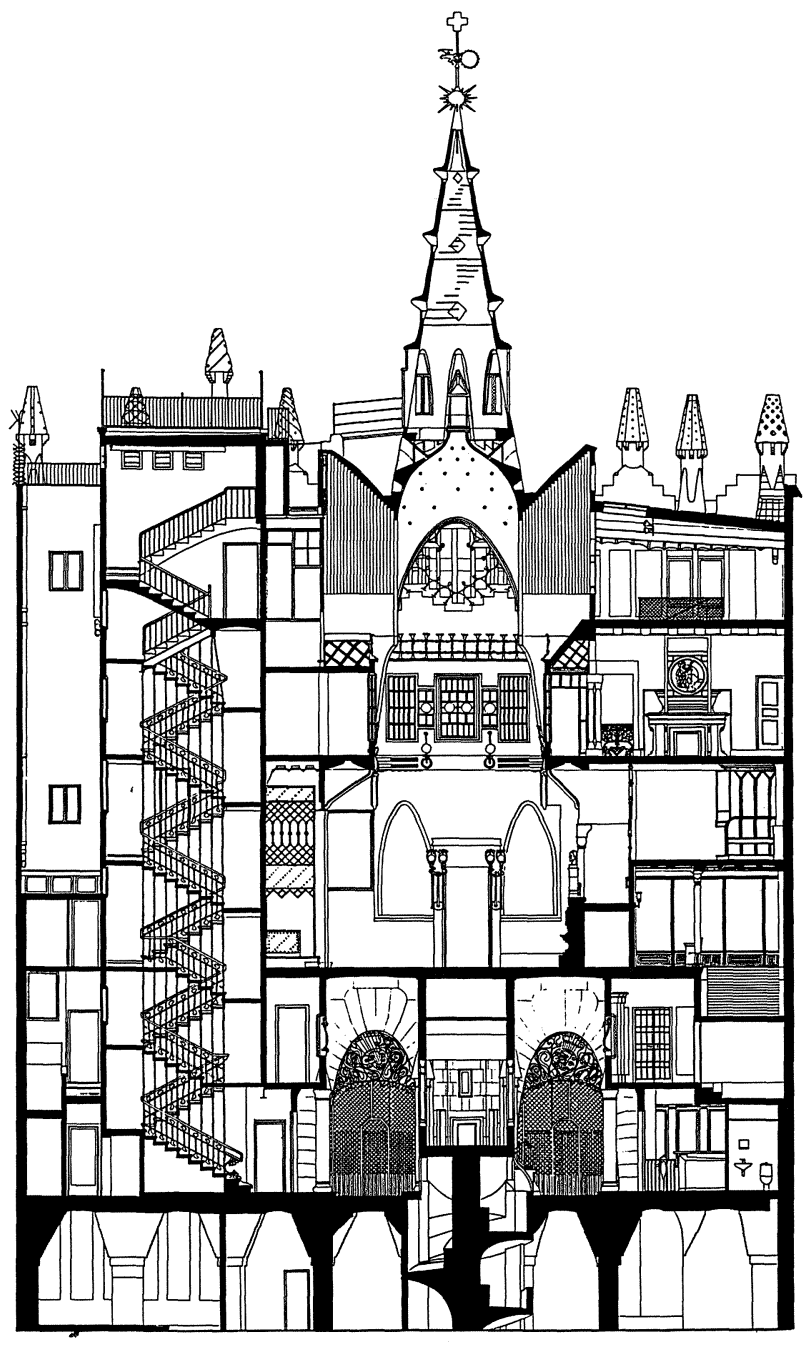

Sección por la escalera de servicio.
El palacio fue utilizado como residencia familiar hasta la guerra civil de 1936, cuando, según parece, fue confiscado. La epopeya del palacio empezó, sin embargo, en la posguerra, al sufrir un patético abandono y estar en un tris de ser derribado. Por fin, en 1945, fue adquirido por la Diputación Provincial de Barcelona, que lo destinó a sede del Instituto del Teatro y lo remozó y abrió sus puertas en 1954.

Ese nuevo uso, tan útil ciertamente para garantizar la pervivencia del palacio, llegaría con el tiempo a ser preocupante, por la degradación del edificio que suponía y porque impedía su correcto disfrute colectivo como patrimonio de la humanidad ${ }^{2}$.

\section{Objetivos y reflexiones}

Cuando en 1982 nos hicimos cargo de la conservación del inmueble, nuestro primer objetivo fue la tarea de mantenimiento que los usuarios habían omitido. Paralelamente, iniciamos la toma de datos para conocer mejor el edificio y poder recuperar su autenticidad (entendida no tanto en función de la originalidad de la materia como de los aspectos esenciales de la arquitectura: forma, espacio y carácter). Cuando se comprobó la relación innegable entre la mala conservación y el uso inadecuado, los trabajos empezaron a tener en cuenta también la posibilidad de dar al edificio un nuevo e inocuo destino.

El uso idóneo de un monumento es aquel para el que fue concebido. Era obvio, sin embargo, que ello era impensable ya en el Palau Güell. Descartados otros usos similares al que tuvo desde 1954, propusimos el más sencillo: convertir el palacio en museo de sí mismo. Una función a la que se tuvo que añadir otras de carácter representativo y cultural que, sin perturbar la función primordial, 


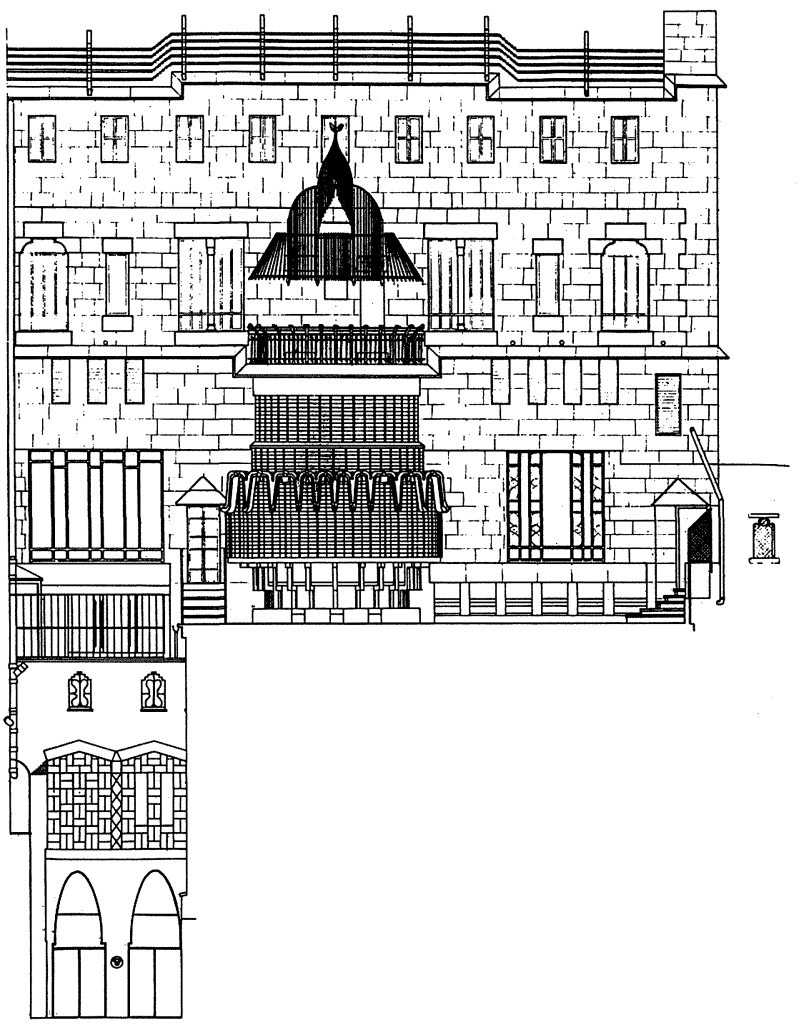

Fachada al patio de manzana.

permitieran dotar el edificio de recursos ordinarios de mantenimiento. Ese nuevo destino nos obligaría a intervenir en el edificio con criterios más que de conservación, de genuina restauración.

A propósito de su actuación en 1904 en la catedral de Mallorca, Gaudí recordó que restaurar es, fundamentalmente, lo que él planteó allí: "Volver las cosas a su lugar y a su verdadera función" ${ }^{3}$. Con ese espíritu, tan ajeno a la mera conservación, hemos actuado nosotros en el palacio que él proyectó. También hemos partido del convencimiento de que en restauración hay que actuar-como decía don Leopoldo Torres Balbás- "con eclecticismo y elasticidad" 4.

En la reforma de algunos elementos y el diseño de otros exigidos por el cambio de lugar y función hemos tenido presente las enseñanzas del propio Gaudí ("al restaurar -dijo en referencia a la actua-

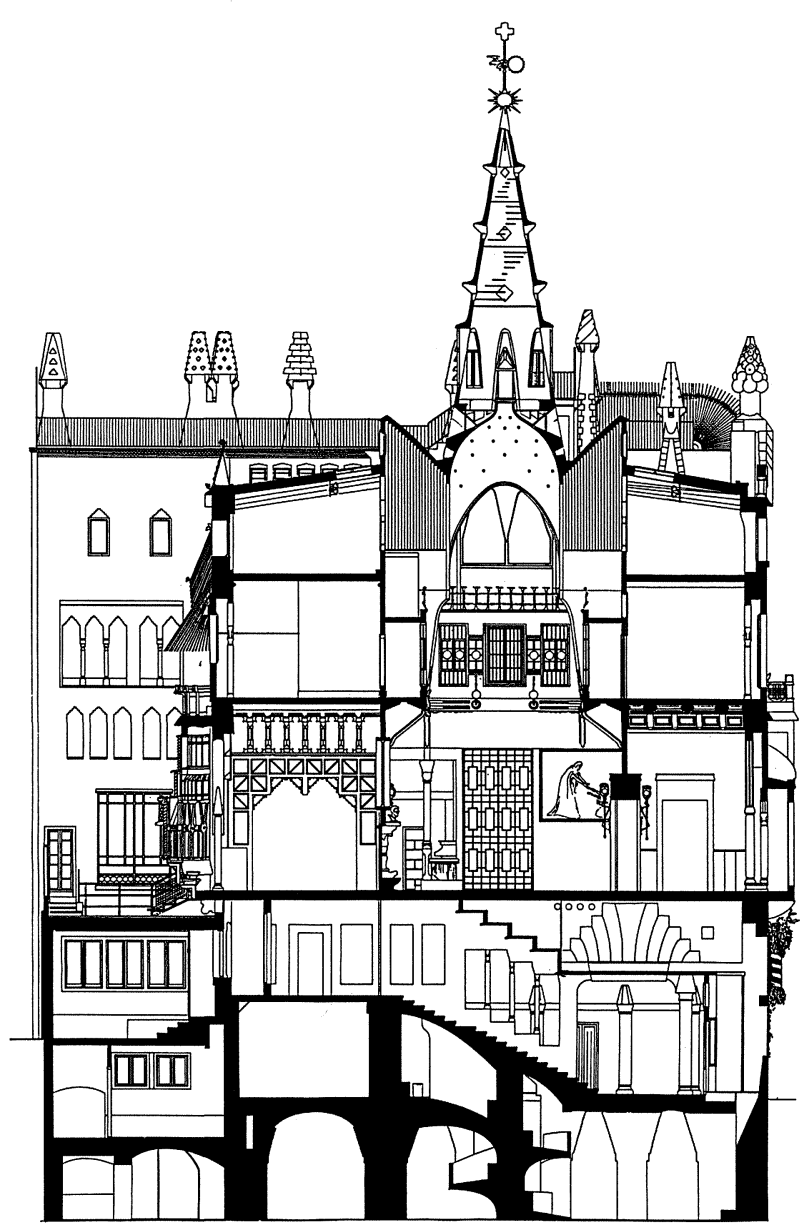

Sección por la escalera principal.

ción en Mallorca- no es necesario copiar las formas preexistentes, sino producirlas dentro de un determinado carácter, poseyendo su espíritu"), actitud que comporta un análisis crítico del objeto en el que se interviene.

En el planteamiento de las soluciones, en algunos casos hemos optado por una recuperación analógica (sustituir o recuperar el original para mejorarlos mediante elementos análogos); en otros, hemos preferido la diacronía armónica, es decir, la introducción de elementos que pretenden armonizar con los preexistentes, pero manifiestan claramente su diacronía a través del diseño o los materiales. En otros episodios de la obra, sin embargo, para recuperar los elementos constructivos, decorativos o espaciales deteriorados o perdidos, nos basamos en el principio de reconstrucción mimética, y rehicimos esos elementos con la máxima fidelidad posible al proyecto o la intención genuinos. 
Éstos han sido los principales objetivos, premisas y criterios de unos trabajos basados en la metodología del Servicio 5 , que a nosotros nos gusta definir como proceso metodológico y crítico de conservación.

\section{La lectura previa}

Los estudios que comúnmente denominamos lectura previa del monumento se han desarrollado en este caso a lo largo de toda la obra y se han referido, como es habitual, tanto a los aspectos históricos (el conocimiento y análisis de la génesis, realización, transformaciones y utilización del edificio), como a los más genuinamente arquitectónicos (constructivos, compositivos, espaciales y de uso).

Una parte importante de estos estudios ha tratado de la estructura del edificio. La imaginativa arquitectura de Gaudí aprovecha hasta sus límites estéticos y estáticos los materiales y sistemas tradicionales, por lo que no son impensables tensiones entre las propuestas plásticas y su materialización. En el Palau Güell, nos pareció que esa tensión podía manifestarse de manera especial en la estructura sustentante. Por ello el Servicio encargó su análisis a los arquitectos Joan Margarit y Carles Buxadé. De su dictamen, que fue ampliamente difundido, se desprendía que Gaudí había resuelto de manera "confusa" aquella estructura, lo que daba pie a los catedráticos a poner en tela de juicio el reconocimiento universal de la obra del maestro.

Diez años de trabajo en el palacio nos permiten hoy opinar que aquella estructura no es confusa, sino simplemente compleja, y que fue concebida por el joven Gaudí como un mecanismo al servicio de la construcción de una idea espacial y formal -como, por otra parte, era habitual hasta el Movimiento Moderno-, es decir, subsidiariamente de lo que es esencial en arquitectura. El análisis numérico que realiza actualmente el ingeniero Giorgio Croci, profesor de la Universidad La Sapienza de Roma, parece avalar nuestra opinión.

Los estudios encargados al profesor Croci incluyen también el seguimiento del comportamiento del edificio. Las próximas fases de restauración, que afectarán el interior del palacio, se proyectarán una vez concluyan estos trabajos. El análisis constructivo del palacio, sin embargo, no finalizará hasta acabar los trabajos de restauración, ya que una gran parte de la información sobre la obra original no se consigue

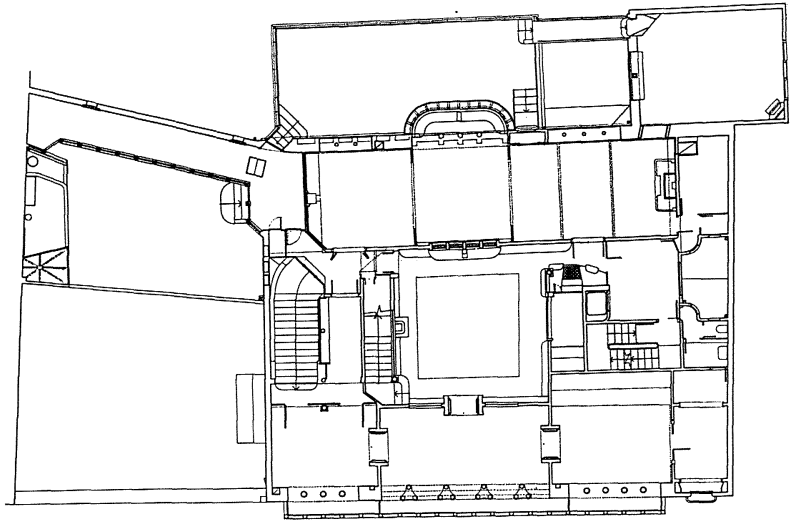

Planta noble del palacio. En el centro, el patio cubierto en torno al cual se desarrollan las dependencias. A la izquierda, el corredor que unia el palacio con la antigua Casa Güell de la Rambla.

hasta que, en el curso de los trabajos, es necesario desmontar o remover las fábricas, momento que se aprovecha para la toma de datos, a menudo llena de sorpresas. Estas indagaciones se reflejan en tres series de planos referidas, la primera, al estado -algunas veces forzosamente hipotético- del edificio en 1890 (cuando acabó su construcción) y, las otras dos, a cómo encontramos el palacio en 1982 y a la situación en que queda después de nuestra intervención. Estos planos constituyen la base del atlas bistórico-constructivo que preparamos.

\section{Los trabajos de restauración}

Durante algunos años la escasez de los presupuestos disponibles limitaron los trabajos de conservación a algunas reparaciones y limpiezas, como las de la fachada principal. Desde 1986, las aportaciones económicas de la propia Diputación, del ministerio de Cultura y de la Comunidad Europea permitieron una actuación más intensa.

Los trabajos realizados durante estos últimos años han consistido en completar la restauración del exterior (fachadas, terraza y azotea), renovar la red básica de las instalaciones de agua y electricidad (hasta 1990 la línea era de 125 v. y las mangueras para incendios eran un puro adorno), remozar el zaguán, reordenar y mejorar la conserjería para acoger a los visitantes con comodidad, y acomodar mejor a los funcionarios y usuarios del Instituto del Teatro, que durante algunos años permanecerá aún en el palacio, aunque sin usarlo con la intensidad y extensión de antes. 


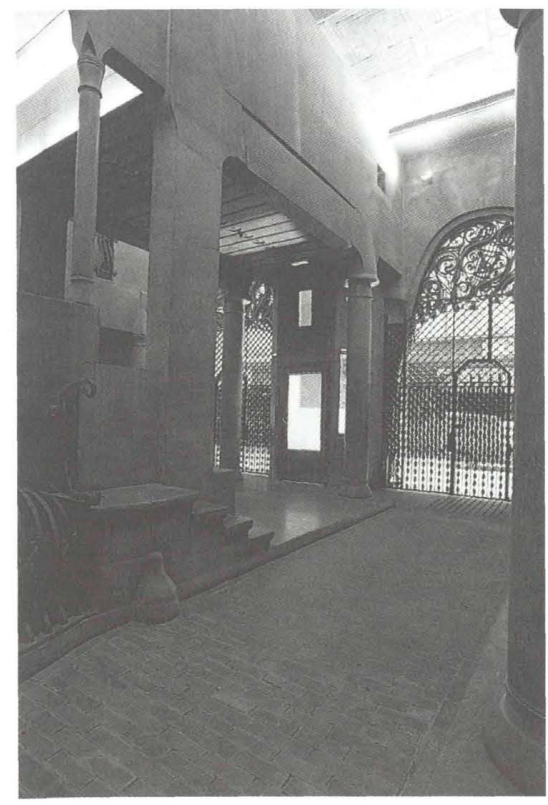

Zaguán. Pavimento de adoquines de pino tea. (Fotografias de Monserrat Baldomá)

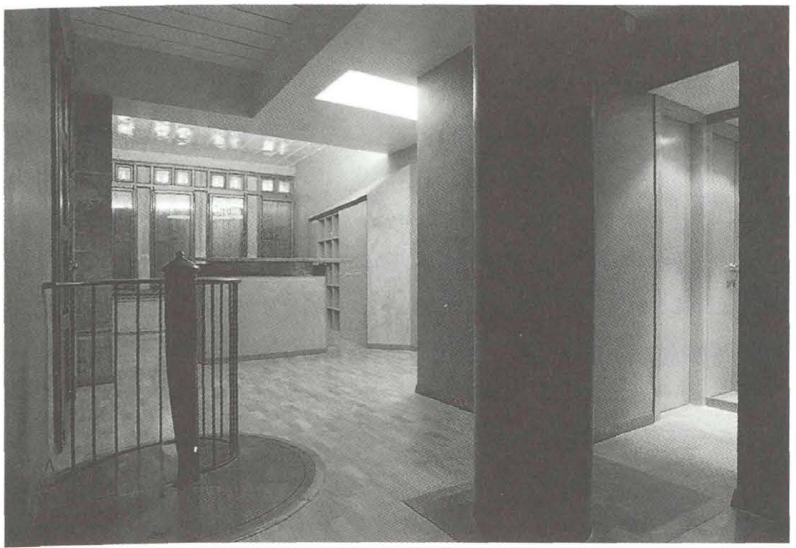

Vista general de la conserjeria. Planta baja. En el centro. la doble entrada de carmajes y la escalera. A la izquierda, la nueva conserjeria.

El remozamiento del vestíbulo consistió básicamente en adecentarlo. Se limpiaron las puertas caladas de hierro forjado (magnífica obra de Joan Oñós, los hermanos Badia y Salvador Gabarró), los techos de ladrillo visto de Agustí Massip, las puertas de madera y hierro forjado, y la piedra calcárea pulimentada de las columnas y del revestimiento de los muros.

Se sustituyó la iluminación de los años cincuenta por otra indirecta que enfatiza la riqueza espacial, y

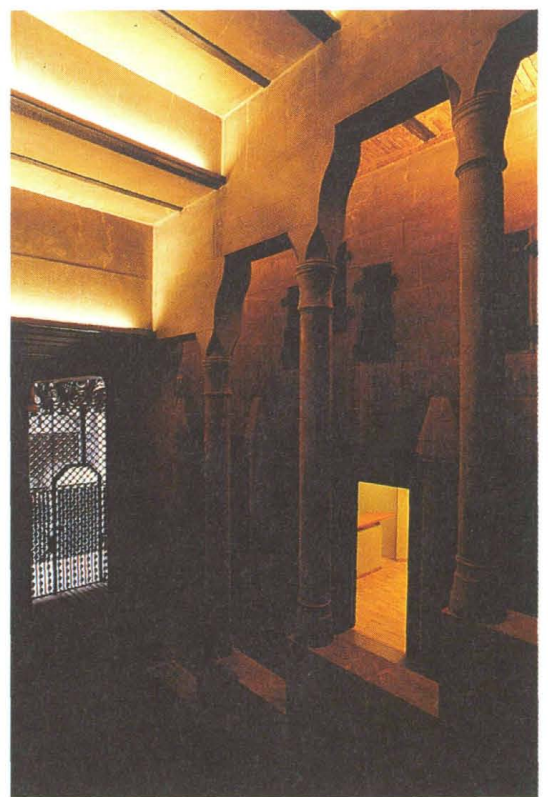

Escalera con la nueva iluminación. A la derecha, la entrada a la nueva conserjería.

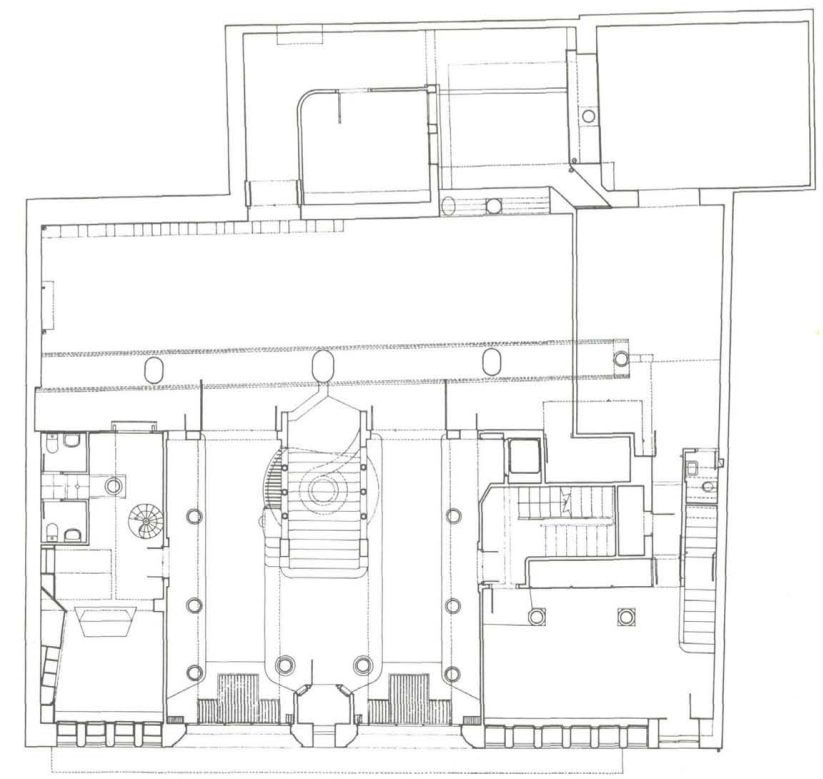

se recuperó y puso en valor el pavimento de adoquines de pino de tea por el que un día transitaron los carruajes. La transformación de la conserjería tuvo que ser más radical. Se tuvieron que colocar los retretes para el público y disponer una zona de recepción que fue amueblada con elementos fijos (armario y mostrador) diseñados por el arquitecto Pablo Carbó. La iluminación, los solados, los techos y los paramentos verticales (revestidos ahora de estuco en frío) fueron totalmente renovados. 


\section{La fachada del patio}

La restauración de la fachada que abre el palacio al interior de la manzana, cabe incluirla en los trabajos de reconstrucción mimética. Se repararon las carpinterías de todas las ventanas, tanto las de la fachada del cuerpo principal como las del cuerpo de servicio, y se repusieron todas las persiana;
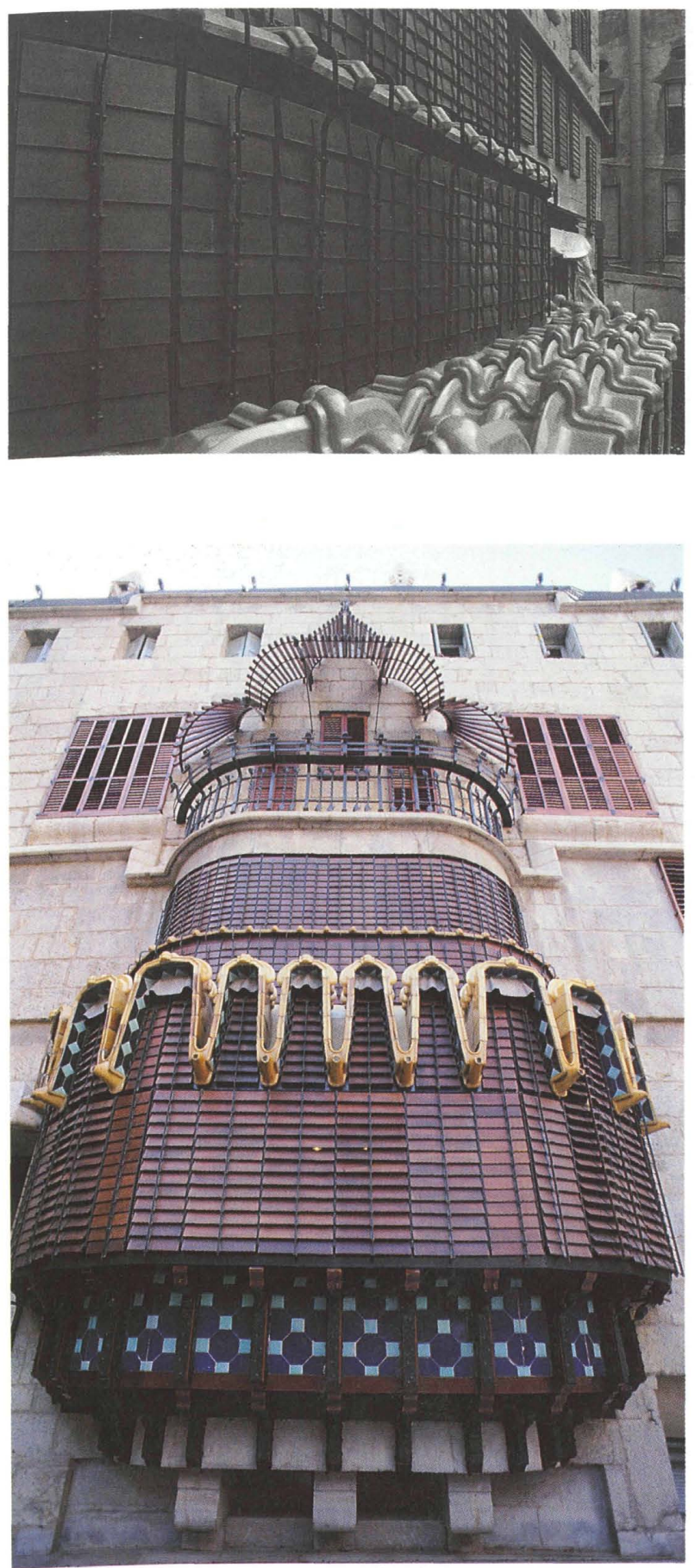

Tribuna de la fachada de mediodía después de la restauración. En la foto de arriba, piezas de cerámica vidriada y lamas de madera de caoba. desaparecidas, realizadas con maderas nobles según el modelo original de Eudald Puntí y Antoni Oliva. Se desmontó y volvió a hacer el umbráculo (la madera que encontramos - muy deteriorada, por cierto- ya no era la original, sino la que la sustituyó hacia 1970), y en la tribuna se cambiaron por otras nuevas idénticas algunas piezas estructurales de madera, las lamas de caoba, las cerámicas vidriadas deterioradas y los hierros forjados. En el interior de la tribuna, se ha forrado de nuevo el respaldo del banco con cordobán trabajado en Córdoba siguiendo el diseño original que pudimos deducir de la información fotográfica que se conserva.

La limpieza de la piedra calcárea de Garraf de esta fachada fue la piedra de toque respecto de las tentadoras ofertas del mercado referentes a milagrosos productos y técnicas terapéuticas aplicadas a la restauración monumental. Se probó, sin éxito, todo lo que el mercado especializado nos ofreció, y decidimos finalmente emplear un lavavajillas. Naturalmente, la piedra no quedaba tan blanca como nos prometían los vendedores de productos, pero nosotros sólo pretendíamos limpiarla. La experiencia fue decisiva para convencernos de que, en general, es preferible optar en estos menesteres por los sistemas y materiales tradicionales.

En la terraza contigua a esta fachada, con ese mismo criterio de reconstrucción mimética, se han recuperado también las escaleras, las barandillas, los toldos -y algún día volverán las enredaderas-, para intentar, si no devolver al palacio un uso ya impensable, sí al menos contribuir a recuperar la memoria de ese perdido uso primigenio.

El pavimento de la terraza nos planteó un dilema. En la restauración de 1970 se había sustituido el original de piedra de Garraf (extraído de las canteras que allí poseía el señor Güell) por uno de piedra menos porosa, mucho más indicada para el exterior. Este solado llegó a nuestros días en mal estado debido a movimientos estructurales del forjado, y decidimos renovarlo. Dudamos si hacerlo con piedra de Garraf o bien optar de nuevo por la utilizada en 1970. La fidelidad a la idea de Gaudí de que todo el material empleado en la casa proviniera de propiedades del promotor ("todos los materiales fueron arrancados del seno de nuestra tierra", exclama satisfecho el articulista de la revista "La Ilustración" al comentar el edificio ${ }^{\circ}$ ) nos pareció prioritaria. El forjado fue reparado sin sustituirlo -buena parte del subterráneo situado debajo no pertenece al palacio-, para lo que se reforzó la viguería original mediante conectores. 
En la recuperación de la celosía reticular perimetral -que resultaba imprescindible para devolver la privacidad perdida a la terraza- no dudamos, sin embargo, en anteponer los requerimientos del nuevo uso público del palacio a los criterios de fidelidad al original. La nueva celosía está obrada en madera noble, muy distinta por tanto a la sencilla celosía primitiva desaparecida que conocíamos por fotografías.

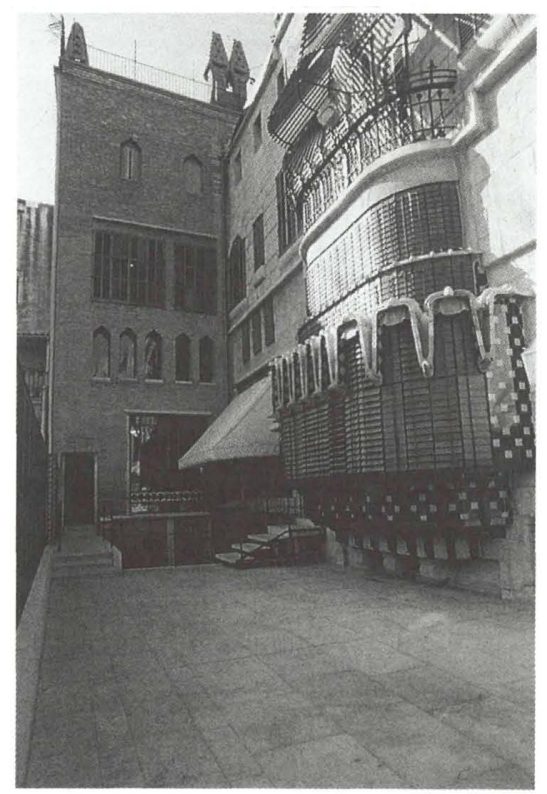

Terraza de la fachada interior: pavimento de piedra calcárea de Garraf y celosía de madera africana. Arriba, extracción de piedra en el macizo de Garraf.

\section{La cubierta fantástica}

Este principio de eclecticismo y elasticidad con el que planteamos nuestra actuación ha presidido también la intervención en la cubierta, uno de los lugares más bellos del palacio, pero también donde la mano de Gaudí se muestra titubeante, al mezclar soluciones brillantes de diseño con otras menos acertadas desde el punto de vista constructivo. En la cubierta, pues, era donde la intangibilidad del monumento se hacía más improcedente y donde el diálogo con el objeto heredado era más necesario y deseable.

A grandes rasgos, la cubierta del palacio es una azotea normal, como tantas otras propias de un clima mediterráneo como el de Barcelona. Pero se trata de una azotea fantástica (es decir, "creada por la imaginación"), ya que Gaudí recreó imaginativamente sus elementos habituales: las chimeneas -transformadas en bellas esculturas de ladrillo visto o decoradas
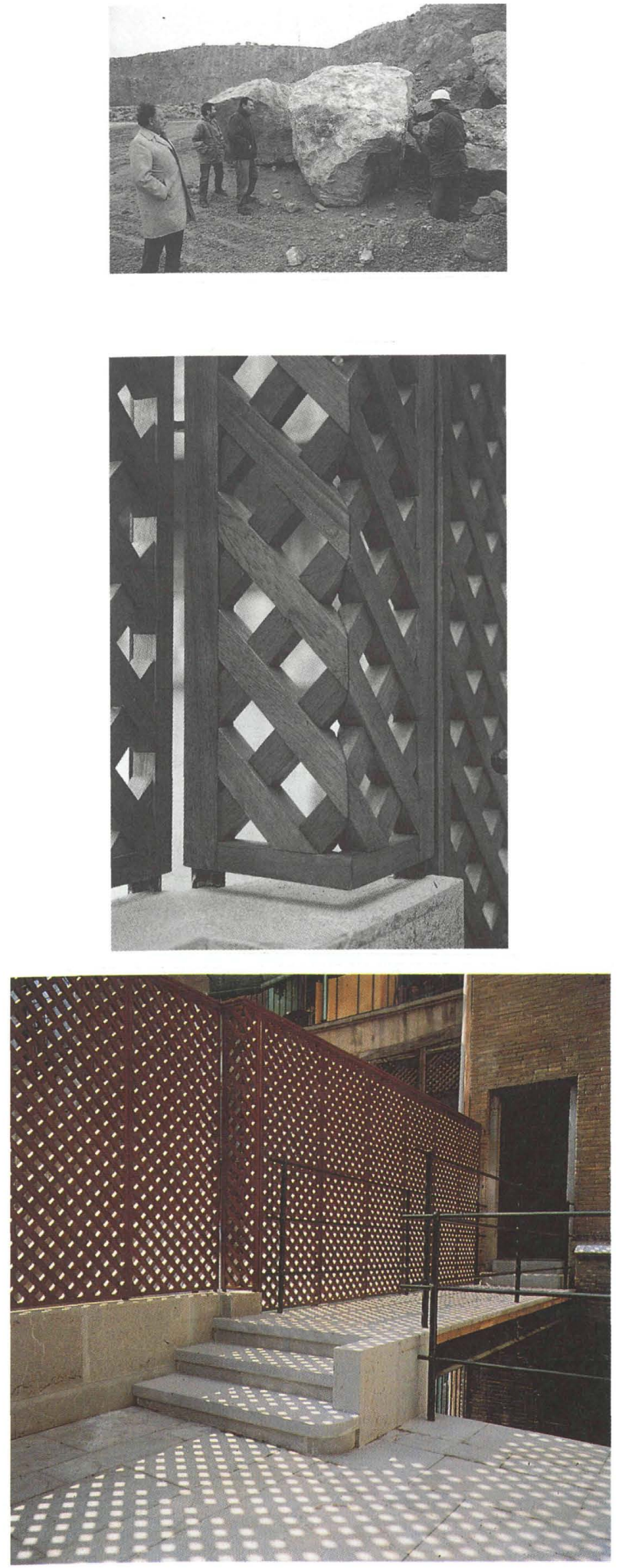

(con trencadís, mármol, vidrio, loza o piedra)- se esparcen sobre un solado levemente ondulante rasgado por cuatro conchas que, buscando la luz, rodean una singular linterna-aguja coniforme coronada por una sorprendente veleta-pararrayos. 
Nuestra actuación en la azotea se planteó de forma que no se perdiera su singular carácter - la atractiva mezcla de terraza de servicio doméstico y de museo de escultura al aire libre-, pero sin renunciar a favorecer el tránsito de visitantes y la puesta en valor de todos estos elementos singulares, objetivos que sugirieron diversas actitudes derivadas del inevitable análisis crítico de la realidad heredada.

Un primer análisis se refirió a los tragaluces situados junto a tres de las conchas o lunetos, que dificultaban la apreciación del movimiento ondulado del pavimento y la utilización pública de la azotea. En los dibujos originales de Gaudí las lucernas parecen más sencillas y las catas realizadas por los arqueólogos ratificaron la sospecha de que habían
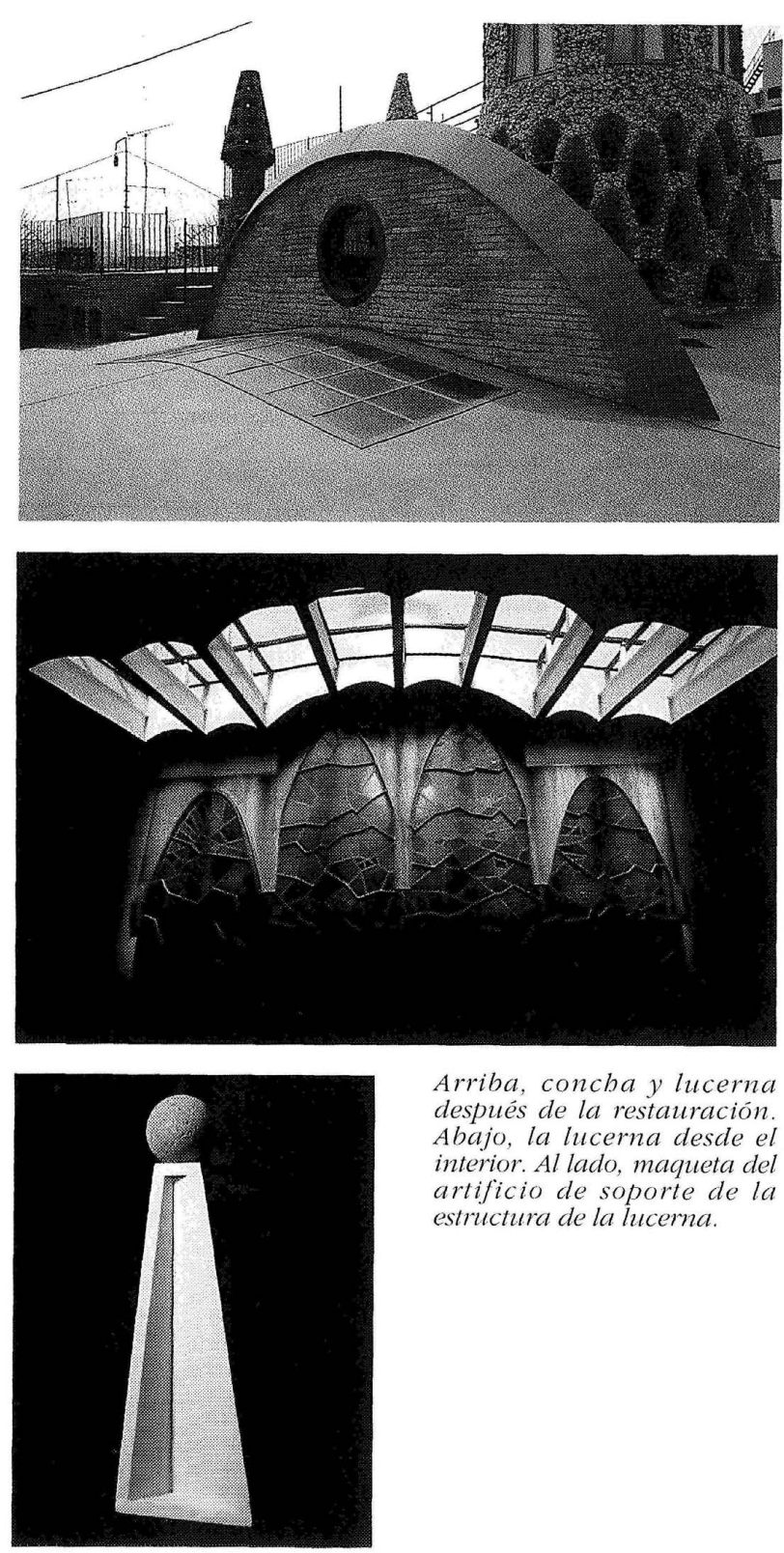

sido elevadas después de su primera construcción. Las claraboyas cuadriculadas de estructura metálica forrada de cobre que nosotros dispusimos -apoyadas sobre la estructura de vigas preexistente mediante un ingenioso artificio diseñado por Pablo Carbó (una figura troncopiramidal coronada por una esfera libre que actúa como articulación) - se adaptan mejor a la superficie ondulante, en una solución conceptualmente más próxima a la prevista en el proyecto inicial de Gaudí.

También pareció oportuno modificar la comprometida situación en que había quedado la concha de poniente a consecuencia de instalar Gaudí en la planta inmediatamente inferior los altos tubos del órgano. El volumen que los acogía superaba la cota
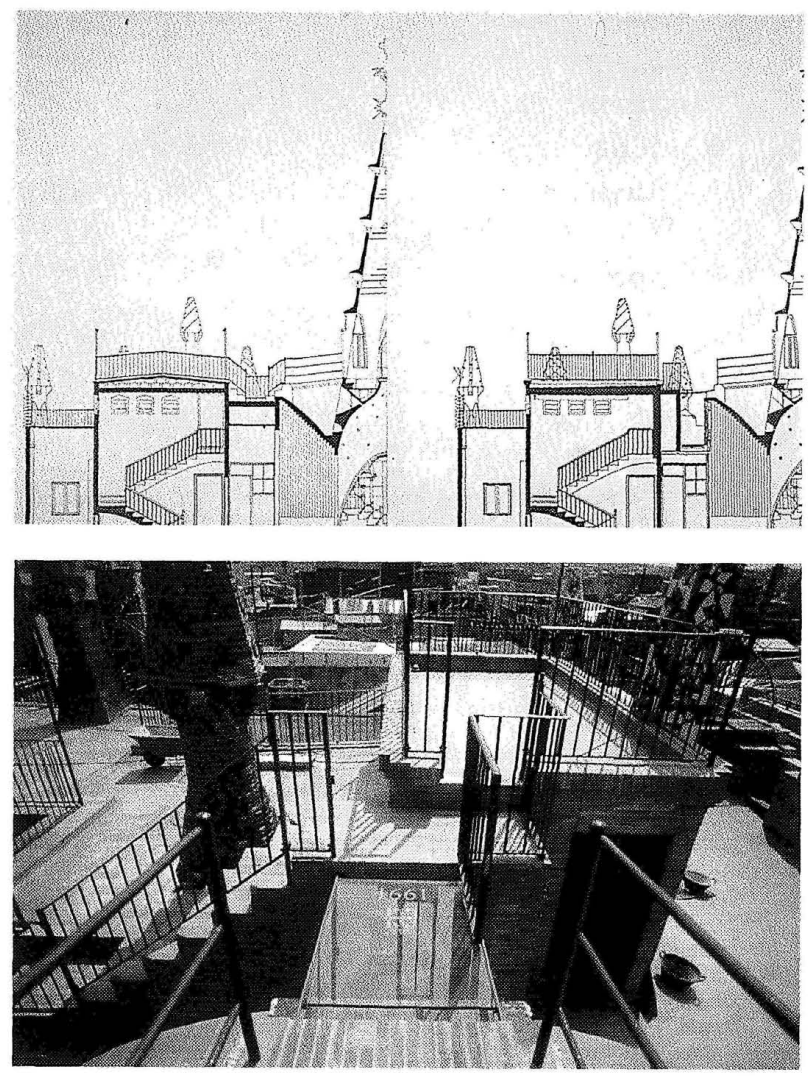

Nuevo ediculo de la escalera y pasarela de paso a la linterna. Arriba, dibujo de la sección antes y después de la restauración.

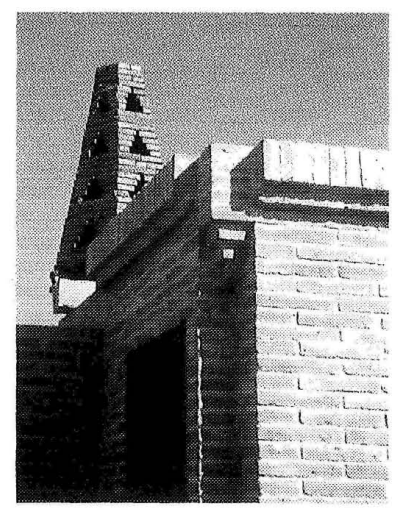


de la azotea, y la concha había quedado ahogada entre ese cuerpo y dos tragaluces elevados que permitían, con dificultad, dar luz a dos bellas y malogradas vidrieras.

El viejo órgano había sido desmontado (atendiendo más al criterio musical del funcionario responsable del palacio que al propio de los arquitectos), y gracias a ello pudimos liberar la concha de esos inconvenientes. Con ello no sólo se ha reforzado la armoniosa relación de la linterna central con los ¿cuatro lunetos que le dan escolta (así como facilitar al visitante, que ahora puede rodearla, nuevas perspectivas de la azotea), sino que también se ha podido dar énfasis a valores espaciales y formales que pasaban desapercibidos. A través del vidrio transparente que cierra ahora el luneto, el espectador descubrirá la belleza de la sucesión escalonada de arcos parabólicos de ladrillo que forman el intradós de la concha, y gozará de nuevas perspectivas oblicuas a través del espacio central del edificio, similares en intención y sensación a las previstas por Gaudí desde tantos otros rincones del palacio.

También aprovechamos esa modificación del luneto meridional para replantear las escaleras de comunicación entre los diferentes niveles y volúmenes de esa parte de la azotea, lo que obligó a remover algunas barandillas. La parte alta del edículo de la caja de la escalera -de torpe dibujo desde su origen, agravado por las modificaciones posterioresse rehizo según el modelo del remate que el propio Gaudí diseñó para un cuerpo del edificio contiguo

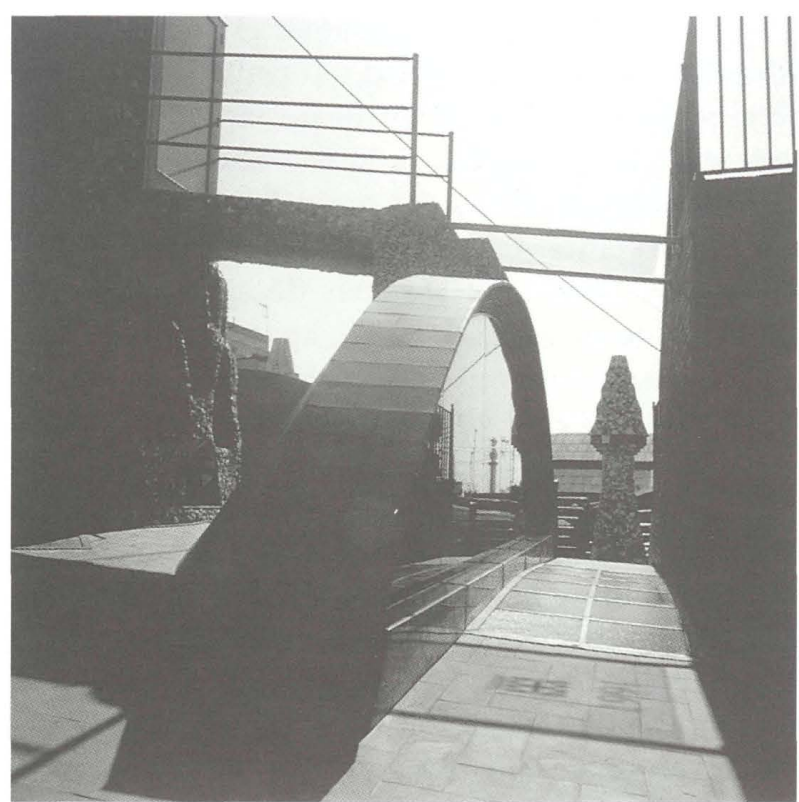

Lucerna de poniente, una vez liberada. En el vidrio, reflejado, el monumento a Colón.

que perteneció posiblemente al palacio en un primer momento. Los materiales empleados en estas reformas son los mismos que se utilizaron en 1888 , ladrillo rojo manual, mortero de cal, madera y hierro forjado.

\section{Azotea con vistas}

La puerta de salida a la azotea se cambió de lugar por dos motivos. Primero porque perjudicaba la chimenea contigua (la número siete) y, por otra parte,

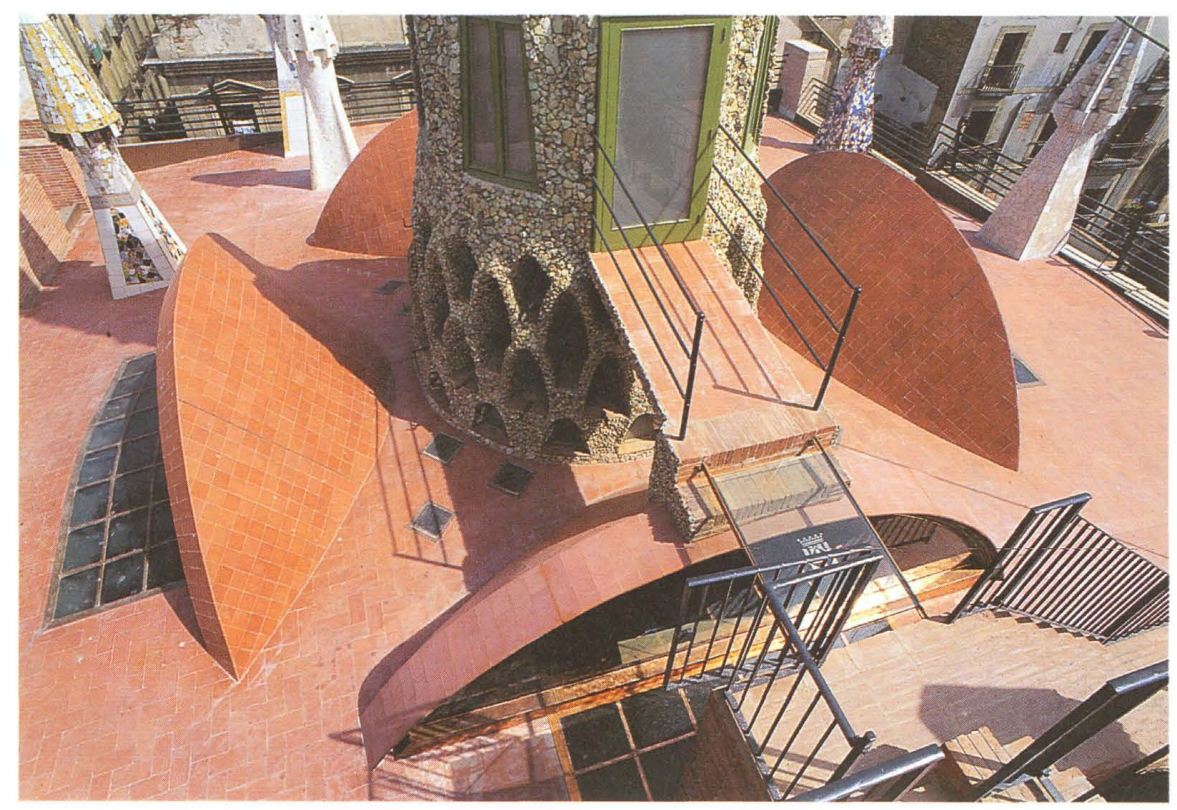

Las cuatro conchas emergen del solado ondulante y rodean la linterna. 
por haber cambiado radicalmente el panorama que divisaba el visitante cuando accedía a la terraza. Orientada la puerta al noroeste, antes aparecían ante ella las chimeneas de la fachada recortadas en el cielo azul en el que se perfilaba la lejana sierra de Collserola tras un paisaje de tejados de la ciudad vieja y del Ensanche. De unas décadas hacia aquí, las chimeneas casi ni se veían, apagado su desdibujado contorno sobre el telón de fondo de la mole levantada sobre el edificio de delante del palacio, un viejo hotel tomado ahora por los japoneses ávidos de emociones. La nueva puerta abierta por nosotros mira al nordeste, y a través de una abertura acristalada se ve en primer término, y como única protagonista, la arquitectura de Gaudí.

La renovación del solado de la azotea, que ya no era el original sino fruto de una restauración de 1972, se hizo con materiales más resistentes (gres y mortero de cemento), e introduciendo mejoras constructivas (como la tela butílica). En cuanto a los aspectos formales se basó en los datos recogidos por los arqueólogos en las catas practicadas, y supuso también la introducción de nuevos elementos de borde realizados en cobre, diseñados poseyendo el espiritu de la sencilla azotea primitiva.

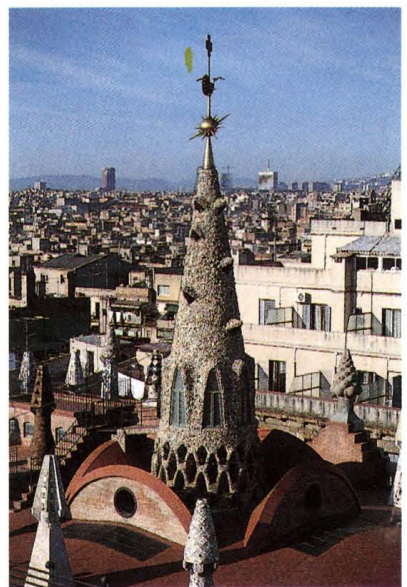

Cúpula-linterna restaurada. Sistema de iluminación y estructura interior.

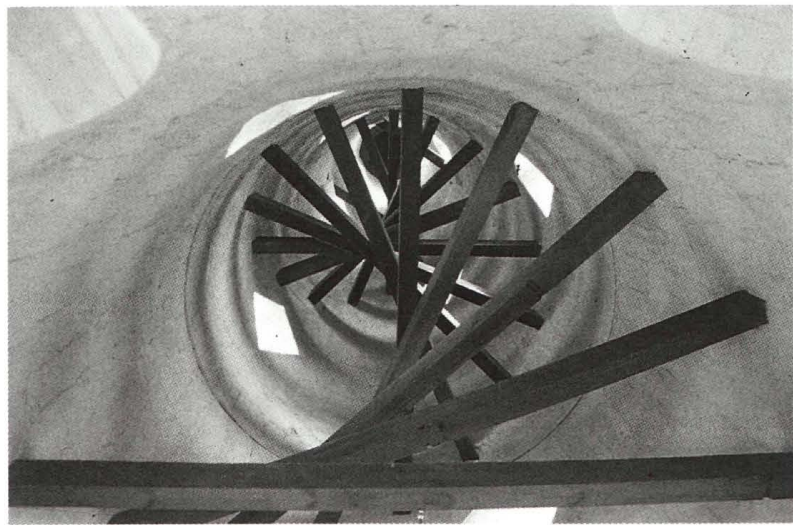

La restauración de la aguja central o linterna nos deparó alguna sorpresa. En todos los tratados referentes al palacio hasta entonces publicados se hacía referencia al vidrio, la cerámica o a materiales sin identificar, al tratar del revestimiento de la aguja, lo que a todas luces era inexacto. Los estudios del aparejador Josep María Moreno nos pusieron sobre la pista certera: se trataba de pequeños fragmentos de piedra arenisca vitrificada provenientes del revestimiento interior de los hornos de cal ya amortizados que se conservaban en la finca de los Güell en Garraf y que Gaudí supo aprovechar de forma genial. Para restaurar el revestimiento de la aguja
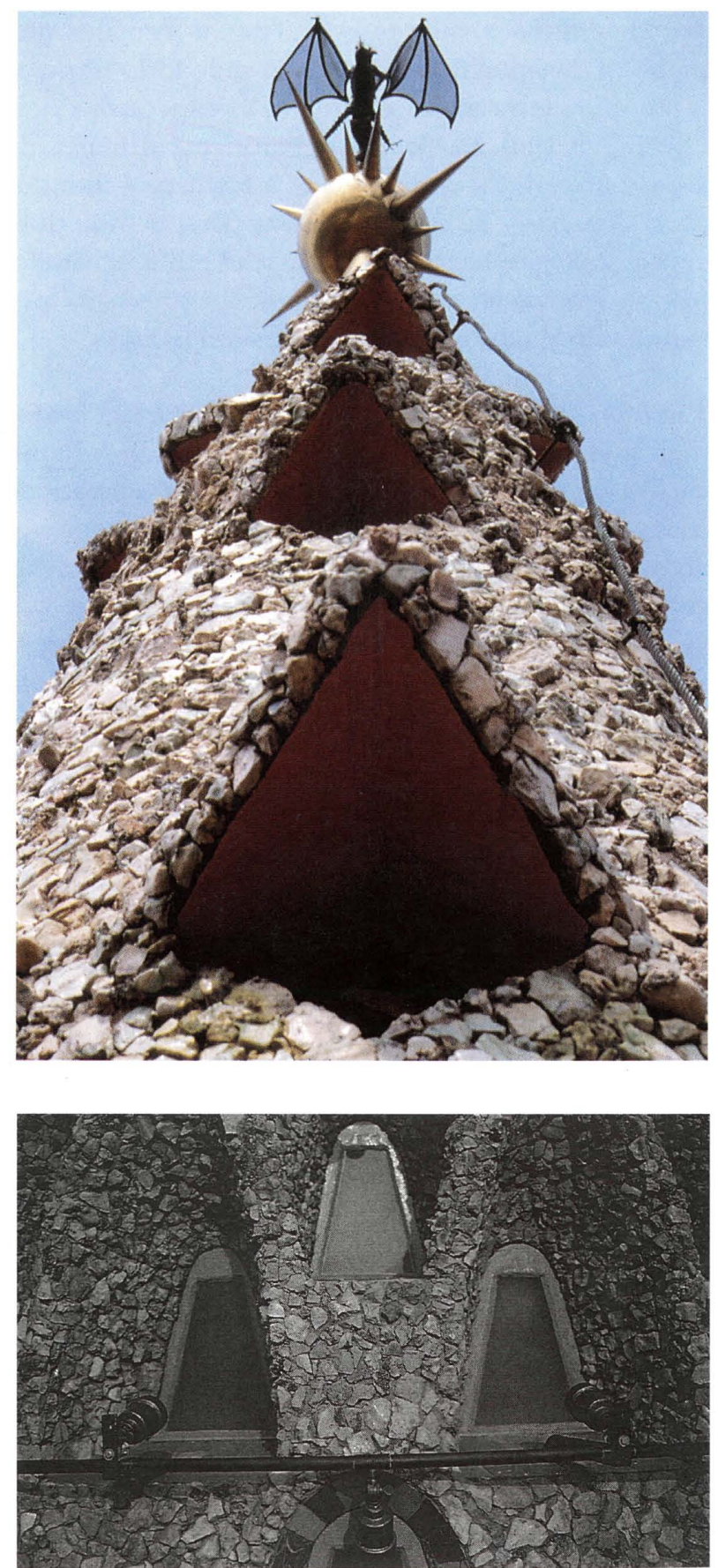
tuvimos que buscar en el macizo de Garraf, y luego comprar y desmontar, otros hornos abandonados.

Más sencilla, aunque también compleja de ejecución, fue la operación de limpieza del elemento que corona la aguja, que se tuvo que desmontar, bajar y transportar al taller. Se pulieron el cono y la esfera y la estrella de los vientos de latón, se limpiaron las puntas de cobre del pararrayos franklin, se repusieron las mallas de latón de las alas del murciélago y el pararrayos-veleta pudo pregonar de nuevo el ingenio de su autor, más digno de atención que la posible simbología del elemento, por la cual siento, lo confieso, poco interés, a pesar de que por ella me interroguen cuantos visitantes acompaño a la azotea.

Recuperar la iluminación artificial de la linterna fue también un objetivo irrenunciable. Que en cada uno de los arquillos de la parte inferior de la aguja hubiera un punto de luz artificial era imprescindible para lograr que desde el interior se percibiera, tanto de día como de noche el efecto de bóveda celestial que quiso Gaudí dar a la linterna. Éramos conscientes de que cualquier artilugio que previéramos para sostener esa instalación iba a afectar negativamente la bella imagen de la cúpula coniforme, y pensamos, como mal menor, reproducir con la máxima fidelidad el sistema original.

No conseguimos, sin embargo, saber cómo eran las lámparas originales (que debieron de ser alimentadas con gas), ni la primitiva instalación eléctrica que se colocó después (la que hallamos nosotros databa de los años cincuenta). Nos conformamos, pues, con utilizar los primitivos elementos de soporte, que se habían conservado, para apoyar dos aros de cobre que rodean la linterna y por los que discurre la instalación eléctrica que sirve a las lámparas que descansan en ellos.

En el interior de la aguja se sanearon los refuerzos estructurales metálicos y la fábrica de ladrillo, y se restauró el mueble original que soporta la luz cenital de la cúpula interior. También se ha conservado la ingeniosa estructura leñosa en espiral que refuerza la estabilidad frente al viento, aunque resulte peligrosa, según los especialistas, ya que puede amplificar el efecto de torsión en caso de seísmo. Los estudios del profesor Croci antes citados persiguen también despejar una de las incógnitas que nos plantea la estructura material del palacio: saber qué le pasaría al edificio si se ve afectado por un seísmo de grado elevado. Es posible que el riesgo sísmico nos obligue a elegir entre la garantía de

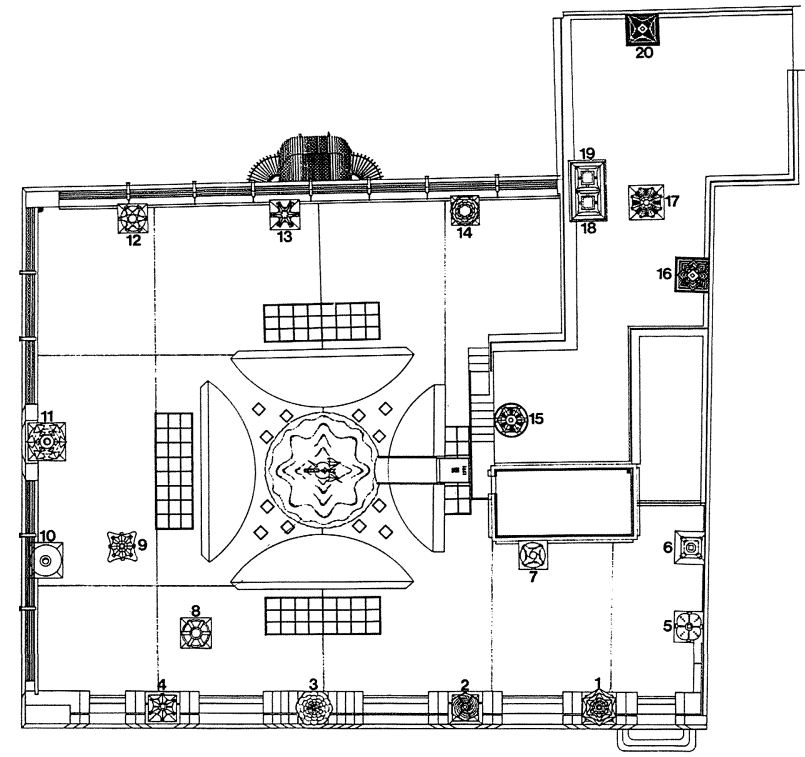

Planta de la azotea después de la restauración, con indicación de las 20 chimeneas.'

conservación o la alteración de la autenticidad formal y espacial del palacio por la introducción de refuerzos inocultables. En ese momento se replantearía la actitud respecto de la estructura.interior de la aguja de la linterna.

\section{Las veinte chimeneas}

Junto al mimetismo o la analogía que han presidido estas actuaciones, en la azotea se dieron algunos casos de diacronía armónica. Uno fue el de la plataforma de cobre y vidrio que une el renovado edículo de la caja de escalera con la rampa de acceso al interior de la linterna. En el vidrio se grabó la fecha de la intervención: 1991. Otros casos se dieron en el tratamiento de las veinte chimeneas de la azotea, en los que se ha vuelto a reproducir ese genéríco eclecticismo y elasticidad, que aconseja adaptar el criterio de actuación a las diversas circunstancias de cada elemento.

Algunas chimeneas, como las de ladrillo visto, habían sufrido graves alteraciones, y para restaurarlas se ha seguido el principio de mimetismo. Un caso significativo ha sido el de la chimenea número 17 , cuyo tronco y caperuza originales se habían perdido. En una restauración anterior se había reconstruido el tronco en forma de prisma, y también una parte del sombrerete copiando el de una chimenea contigua. Analizada con detalle la poca documentación que se conservaba nos dimos cuenta de que esa reconstrucción era errónea. El tronco nunca había sido prismático ni la caperuza de la manera que se rehizo. 

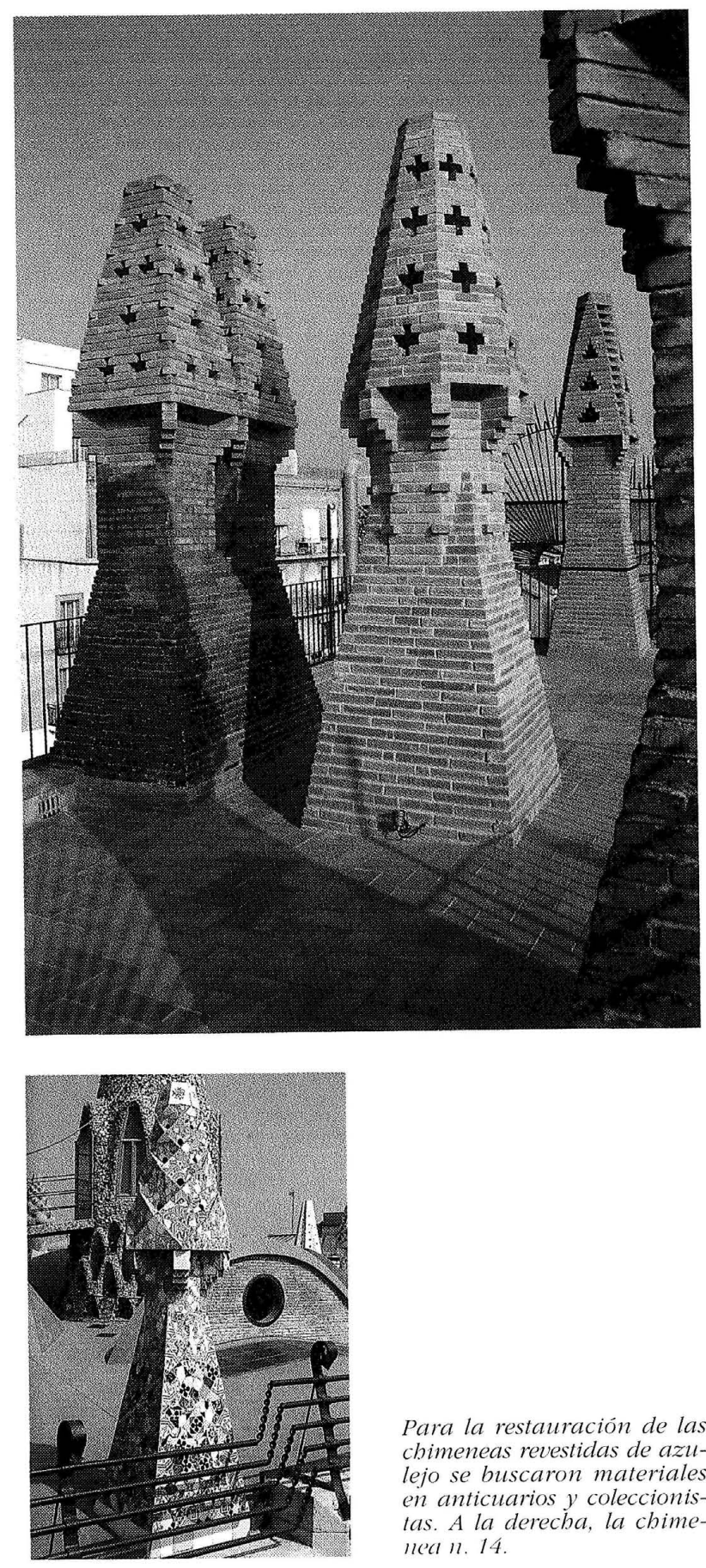

Para la restauración de las chimeneas revestidas de azulejo se buscaron materiales en anticuarios y coleccionistas. A la derecha, la chimenea 11.14.

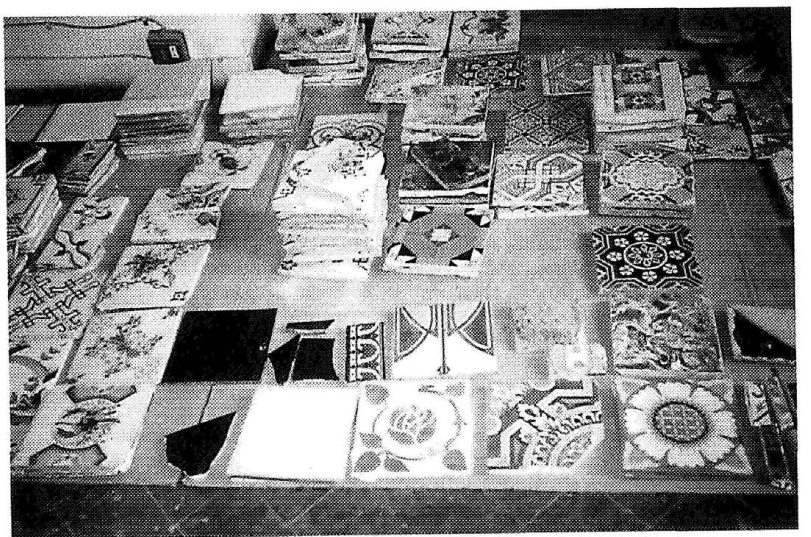

Chimeneas 16, 17 (en el centro), 18, 19 y 20, después de la restauración. Bajo estas líneas, proceso de reconstrucción de la número 17.

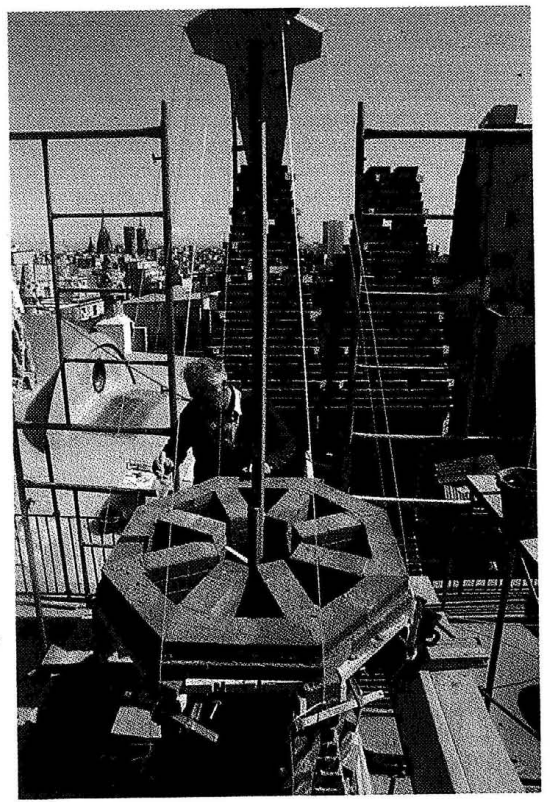

A partir de esa misma documentación dibujamos una versión que creímos más ajustada a la realidad. Desmontamos toda la chimenea, incluida la base, que presentaba algunas grietas, y procedimos a reconstruirla con el mismo tipo de ladrillo. Por fortuna, la habilidad de algunos albañiles de hoy no tiene nada que envidiar a la destreza de los artesanos de la época de Gaudí. Estamos convencidos de que la chimenea número 17 actual es mucho más auténtica que la que nosotros encontramos. Aunque la materia sea ahora totalmente nueva.

Las chimeneas revestidas habían conservado, por lo general, sus características formales, aunque deterioradas. El criterio en éstas ha variado según algunas circunstancias y el grado de deterioro. La restauración de las chimeneas número 10 (cuyo tronco y caperuza estaban revestidos de piedra arenisca como la linterna) y número 13 , toda ella de mármol blanco, no tuvo problema. Se limpiaron y se repusieron las piezas perdidas con el mismo material. Más compleja resultó la restauración de las nueve chimeneas total o parcialmente revestidas de azulejos, en pieza entera, en fragmentos regulares o en trencadis (trozos irregulares procedentes de romper piezas). Como norma, la restauración ha consistido en la consolidación y la limpieza o reposición de los materiales perdidos. Para ello se analizaron compositivamente los trazados y las combinaciones cromáticas, que no eran tan aleatorios como podía 
pensarse, y se documentaron todos los modelos de azulejo que aparecían enteros o fragmentados (estudiamos unos 120, la mayor parte de la fábrica Pujol y Baucis de Esplugues de Llobregat, pero también de Castellón y otros lugares).

Para llenar las lagunas o sustituir piezas deterioradas se emplearon otras idénticas a las originales (en algunos casos conocidas gracias a fotografías), localizadas en ferias y anticuarios, o reproducidas por encargo. Cuando no se disponía del modelo original se emplearon piezas similares en dibujo, cromatismo y antigüedad. Igual se hizo cuando se desconocía el modelo, tratando de armonizar o contrastar con los de las piezas colindantes según fuera el esquema compositivo general.

En el caso de la chimenea número 9, revestida de trozos de loza blanca, se investigó la procedencia de las vajillas (la mayor parte eran de la fábrica
Pickman de Sevilla), y se comprobó cuáles no se habían colocado inicialmente, sino en restauraciones anteriores a la nuestra. Una buena parte de las lagunas se llenaron con las piezas caídas que se conservaban, bien fueran originales, bien más recientes pero similares por su procedencia, forma y tono. Para sustituir las piezas perdidas, o las que se arrancaron por no responder a las características de las originales (una vez comprobado por el mortero de agarre que, efectivamente, estaban ahí desde épocas recientes), se utilizaron fragmentos de vajillas antiguas de las mismas características, aprovechando el fondo plano de los platos, y respetando el trazado original cuando se conocía. Éste no era el caso de la cara del tronco que mira a mar. El nuevo dibujo de ésta imita al de otra de las caras, que sí es original, pero se introdujeron en él algunos signos de contemporaneidad -el logotipo de los Juegos Olímpicos y Cobi, la mascota- para dejar constancia del momento histórico en que se realizó.

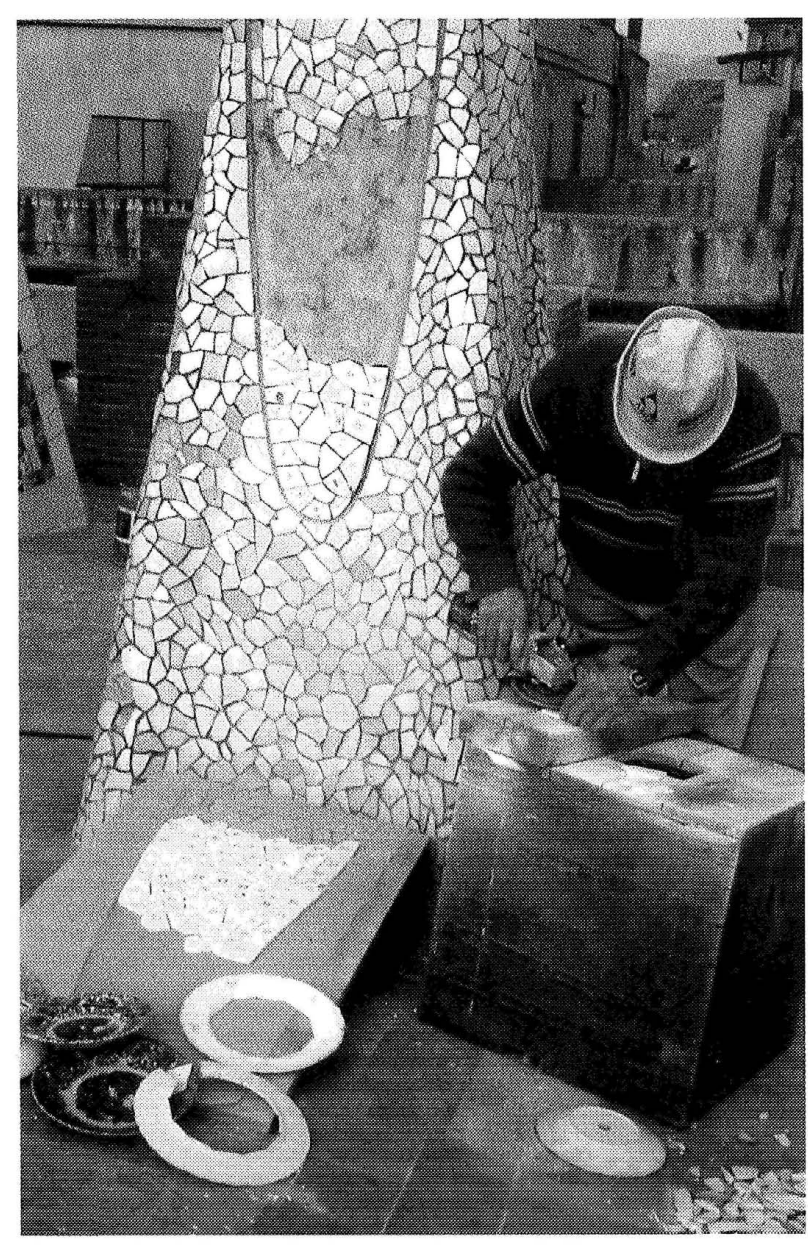

Proceso de restanación de la chimenea mimerog resestida de loza blanca. A la derecha, grafismo conmemorativo del año 1992 en que se bizo la restauración: cabeza de Cobi, mascota olimpica y en la parte inferior; el logotipo de los Juegos.
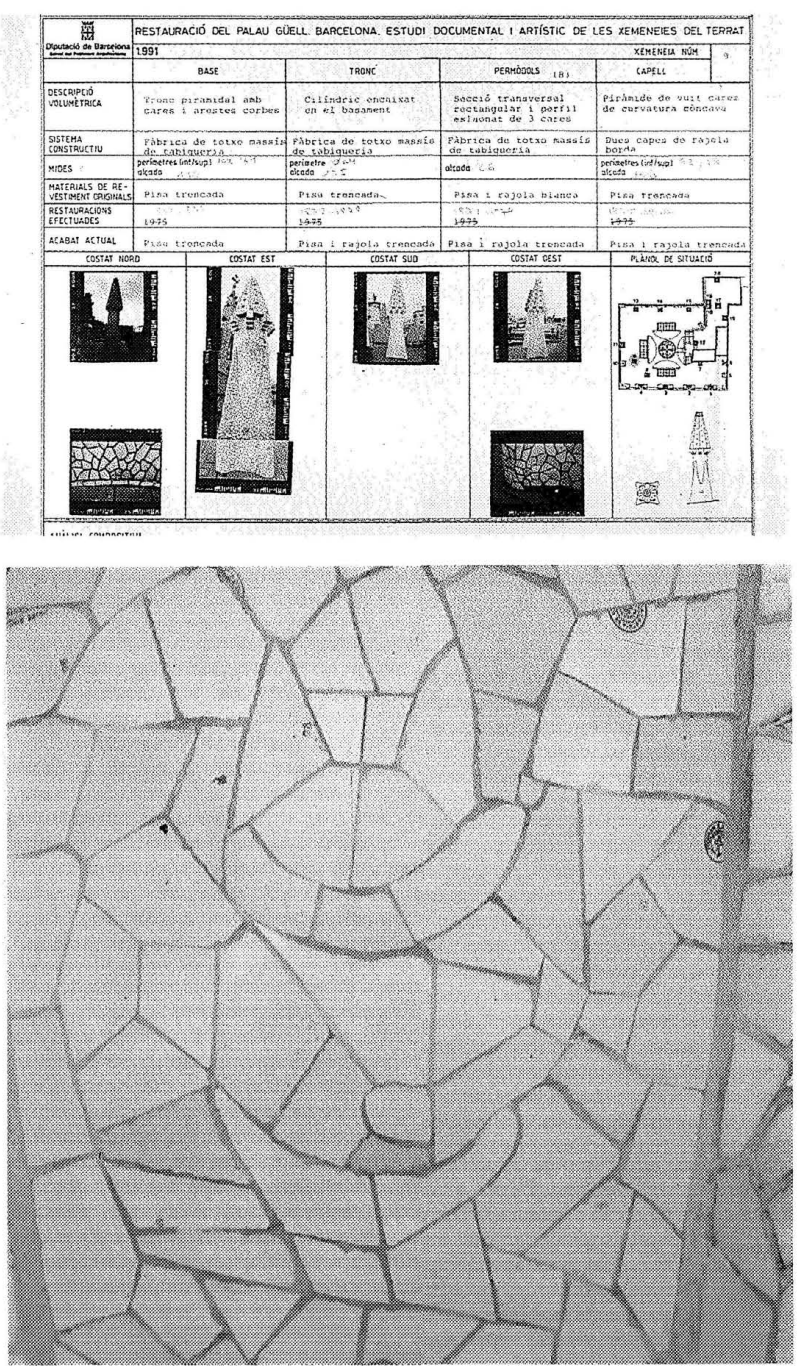


\section{Las caperuzas desnudas}

Un caso distinto, en el que también estaba en juego la autenticidad, era el de las chimeneas que habían perdido con el tiempo el revestimiento inicial de las caperuzas, o las que inicialmente se quedaron sin revestir totalmente no por decisión de Gaudí, sino por alguna causa desconocida. Nuestra reflexión fue ésta: ¿Acaso una chimenea de Gaudí sin revestimiento puede ser considerada auténtica? ¿No es ese revestimiento parte esencial de su autenticidad? Transmitir a las próximas generaciones un elemento diseñado por Gaudí, pero desnudo de decoración, ¿no es transmitir un despojo y no una auténtica creación gaudiniana?

Al estudiar las chimeneas nos dimos cuenta de que en una restauración de los años setenta se decidió llenar los entrepaños de la base de la chimenea número 8, que siempre estuvieron vacíos, con cerá-
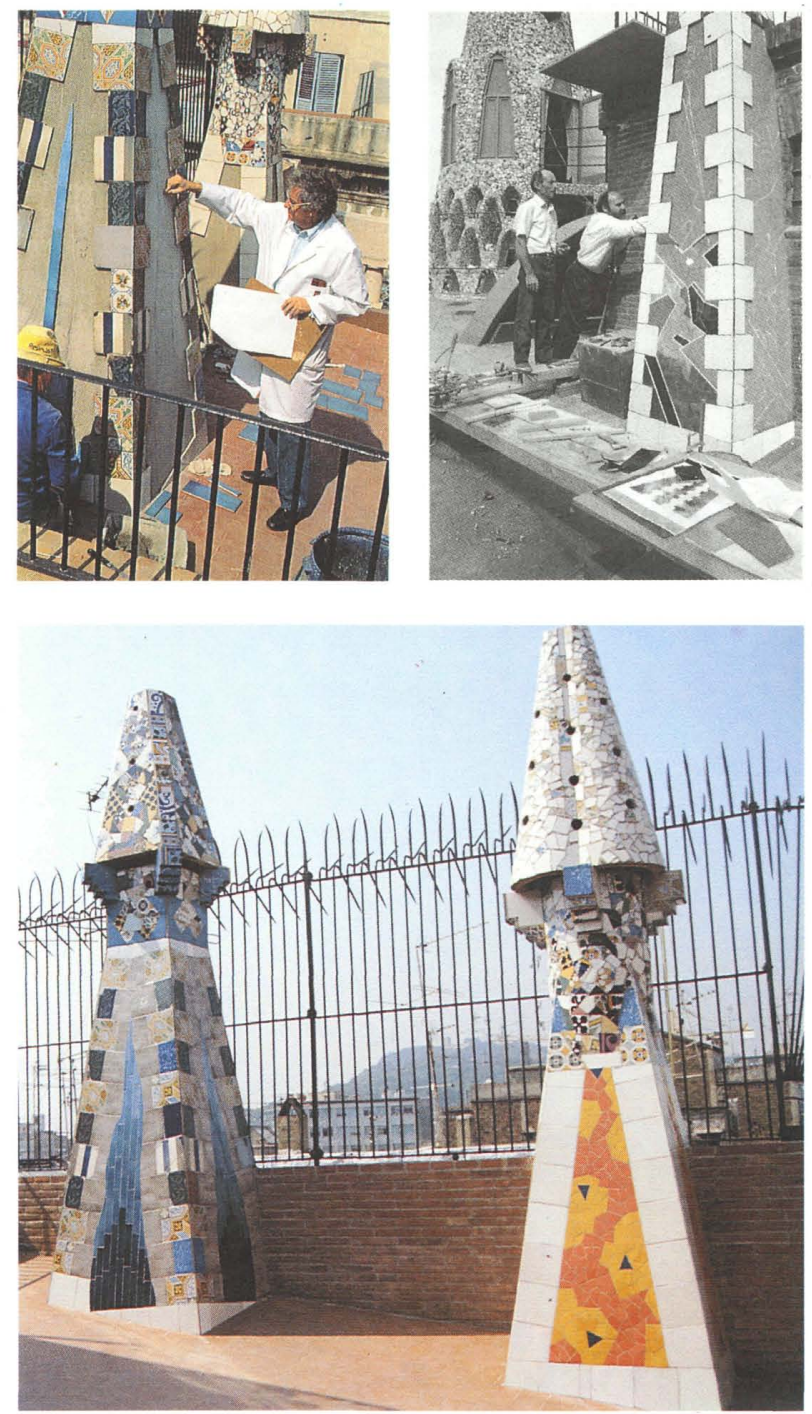

micas propias de aquellos años, fácilmente identificables (aunque no llegamos nunca a saber si este hecho fue intencionado). En cualquier caso, nos pareció acertado el resultado y adoptamos el mismo criterio para actuar en las chimeneas que llegaron a nosotros con entrepaños o caperuzas desnudas.

En cuanto a las chimeneas que sí tuvieron decoración pero la habían perdido, teníamos documentación antigua que nos informaba sobre el tipo de material original y, con más dificultad, sobre el dibujo y la composición primitivos, aunque no, naturalmente, sobre el color. Decidimos recuperar los revestimientos respetando el tipo de material original, y confiamos su diseño a diversos artistas no para que trataran de imitar a Gaudí, sino para que aportaran su propia creatividad como homenaje al maestro. El paisaje de chimeneas podría recuperar así un aspecto esencial de su autenticidad: la textura, el color.

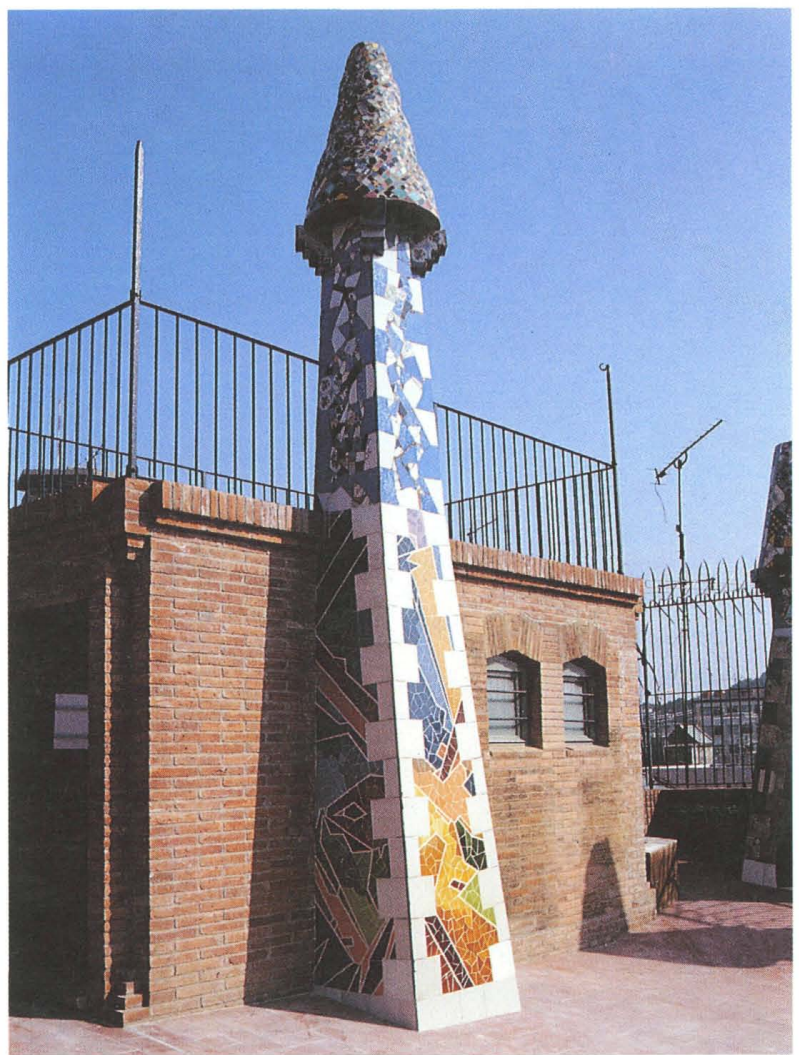

Los troncos de las chimeneas 5 y 6 (en la columna de al lado), fueron diseñados por los arquitectos directores de la obra. En la foto pequeña de la izquierda, Antoni González dibuja la n. 6. El tronco de la $n .7$ (sobre estas líneas) fue obra del arquitecto Domingo García-Pozuelo (en la fotografía pequeña de la derecha, dando las instrucciones), 
Las primeras chimeneas que estrenaron nuevo revestimiento fueron las números 5 y 6 , cuyo tronco tenía azulejos sólo en las aristas. Como se trataba de una primera experiencia nos encargamos del diseño los arquitectos directores de la restauración. A mí me correspondió hacer la propuesta para la número 6. Utilicé cerámicas industriales con diferentes tonos de azul y gris, colores ya presentes en las piezas originales que utilizó Gaudí tanto en la caperuza como en las aristas del tronco. El tipo de material, su corte en tiras alargadas y el dibujo (que recuerda el humo que alguna vez exhaló la chimenea) indican claramente su diacronía con el revestimiento primitivo.

De la chimenea número 5 se cuidó el arquitecto Pablo Carbó. En este caso las aristas originales conservadas eran de pieza entera de color blanco y la respuesta fue una composición contrastada realizada con piezas de colores amarillos y anaranjados,

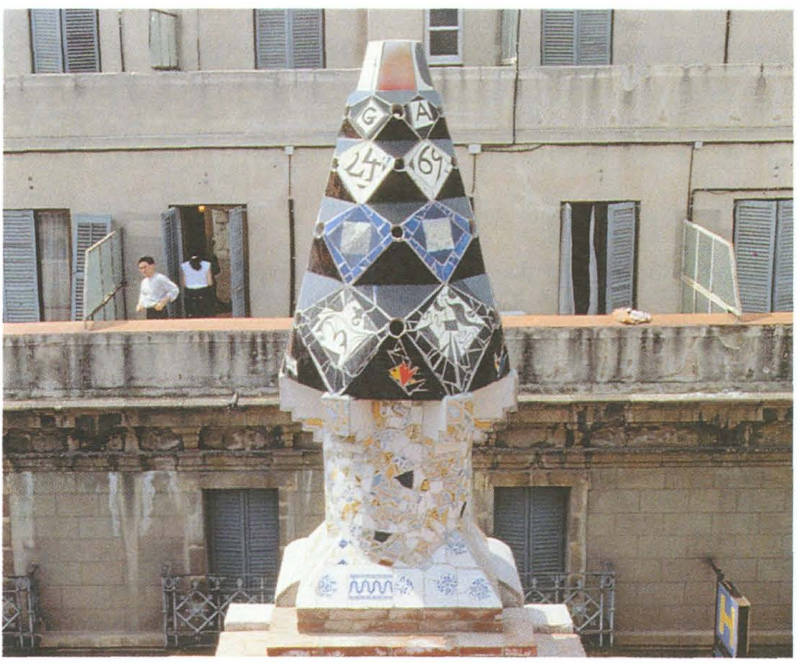

Caperuza de la chimenea número 1 realizada por el ceramista Joan Gardy Artigas (en la fotografia de abajo). Al fondo, el botel Gaudi desde cuyas terrazas los japoneses se extasian ante la obra gaudiniana. La base escalonada de ladrillo de las cuatro chimeneas de la fachada se realizaron en el curso de la restauración.
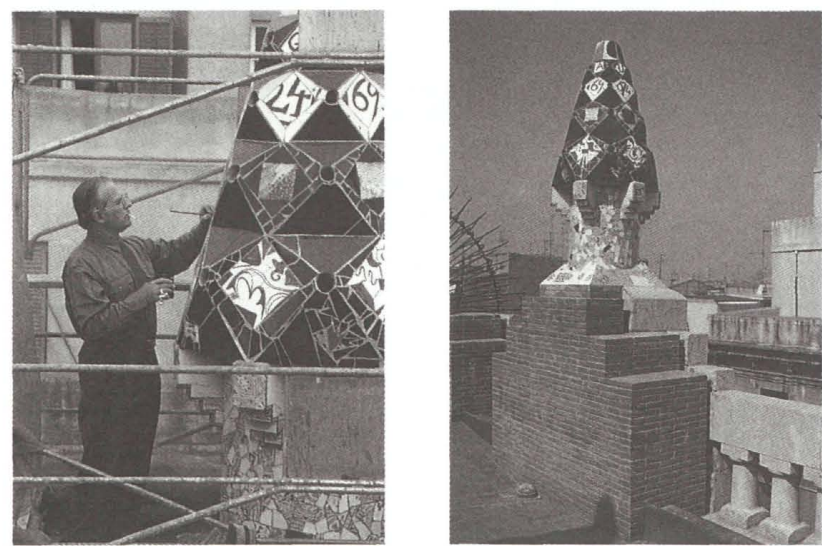

vidriadas expresamente por el taller de Manuel Diestre.

De las cuatro chimeneas de la fachada, que alguien dijo erróneamente que eran blancas a juego con la piedra, sólo se conservaba ya el revestimiento de los troncos (de trencadís cerámico el de la número 1, y el de las otras tres, de trencadis de vidrio), pero sus caperuzas habían estado también revestidas, según delataba la documentación fotográfica conservada.

El diseño del nuevo revestimiento de la caperuza número 1 fue encargado al escultor, ceramista y pintor Joan Gardy Artigas, colaborador de Joan Miró en su última etapa creativa. Una de las condiciones del encargo del nuevo diseño de estas caperuzas fue que no se alterara su geometría y se empleara el mismo material con que fue realizado el primitivo revestimiento. Joan G. Artigas realizó las piezas

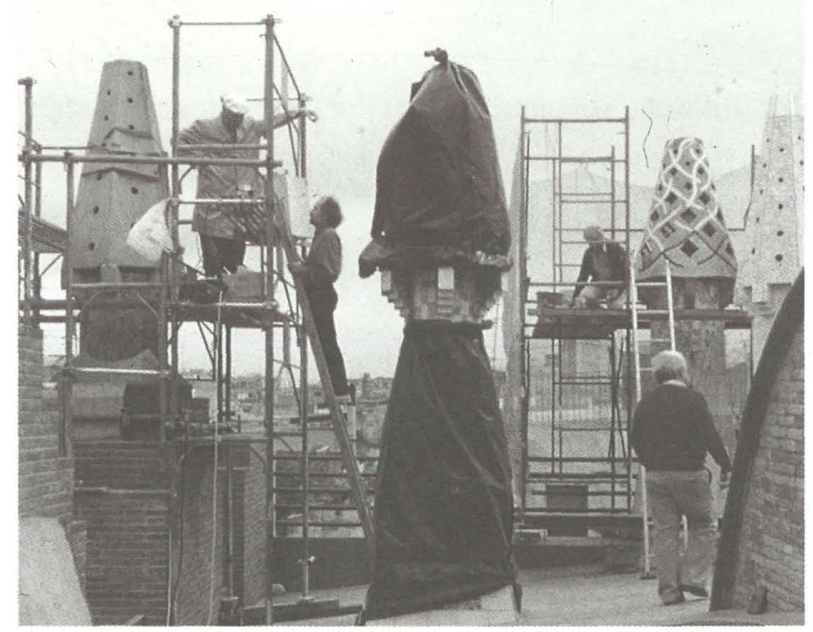

Joan Mora (a la izquierda) y Gustavo Carbó (en la escalera) cuando realizaban, respectivamente, las caperuzas de las chimeneas número 4 (abajo, a la izquierda) y número 10 (abajo, a la derecha).
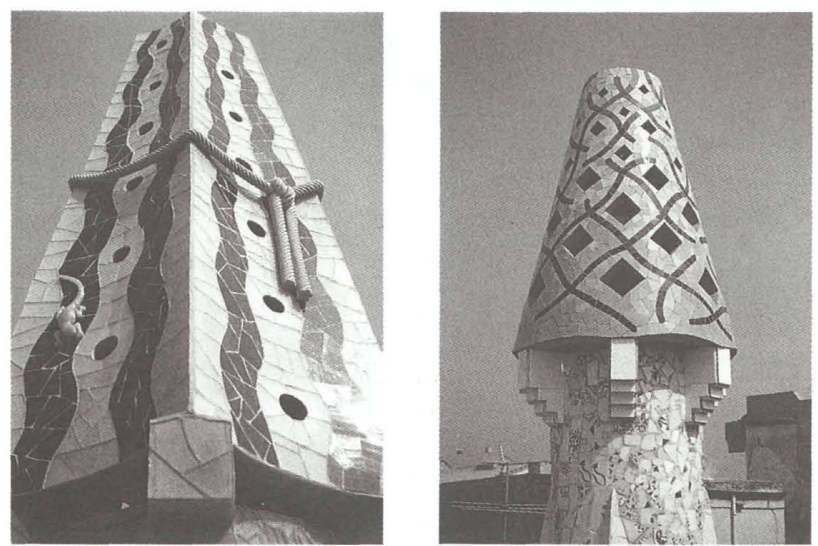
cerámicas en los hornos de la Fundació Llorens Artigas de Gallifa (Barcelona), y fueron colocadas luego en la obra siguiendo fielmente el juego de planos del diseño original del sombrerete.

El escultor barcelonés Joan Mora proyectó el revestimiento de la caperuza número 4 para ser realizado en vidrio gris de diferentes tonos. El material fue preparado por el Centre del Vidre de Barcelona y colocado por los albañiles de la obra. Joan Mora completó su trabajo con dos detalles hiperrealistas en piedra (bien representativos de su quehacer artístico), una lagartija que mira al espectador y una soga que, como abandonada, pende a media altura de la caperuza.

Por último, el sombrerete de la chimenea número 10, de superficie cónica, fue diseñado por el pintor de Cadaqués Gustavo Carbó Berthold, que planteó una composición a base de líneas entrelazadas realizadas con diversos azules sobre fondo de una gama de amarillos, colores presentes en el revestimiento original del tronco y la base.

Las cubiertas de las caperuzas de las chimeneas 2 y 3 , confiadas respectivamente a los pintores barcelo- neses Robert Llimós y Joan Pere Viladecans, no fueron realizadas. En el primer caso, se llegó a presentar y aceptar el proyecto y a hacer acopio de los materiales, pero fuera del plazo conveniente, por lo que la ejecución ha quedado aplazada para cuando se disponga de nuevos recursos. En el caso de la chimenea 3 no se llegaron a precisar con exactitud los motivos del desistimiento súbito del artista.

La capa superficial de los troncos de las chimeneas 2, 3 y 4 , en los tres casos de trencadís de vidrio, fue rehecho bajo la dirección de los arquitectos de la obra, que rediseñamos también las peanas de las cuatro chimeneas de la fachada principal con un grafismo en ladrillo visto que sigue el del paramento de piedra.

El tronco de la chimenea número 7 , que se apoya en el edículo de la caja de escalera, tenía revestidas únicamente las aristas. El diseño de los tres entrepaños fue confiado a Domingo García-Pozuelo, arquitecto y pintor murciano residente en la Rioja, quien a partir de una idea figurativa dibujó una composición abstracta que se materializó mediante azulejos manuales de veinte colores y tonos distintos fabricados también por Manuel Diestre.

Sector nordeste de la azotea. A la izquierda, la chimenea n. 4, con la caperuza diseñada por Joan Mora. En primer plano, la chimenea $n$. 8. A su derecha, la n. 9, revestida de loza blanca. Al fondo, entre la 8 y la 9, la chimenea n. 10 cuya caperuza diseñó Gustavo Carbó. A la derecha, la $n$. 11 revestida con trozos de arenisca vitrificada.

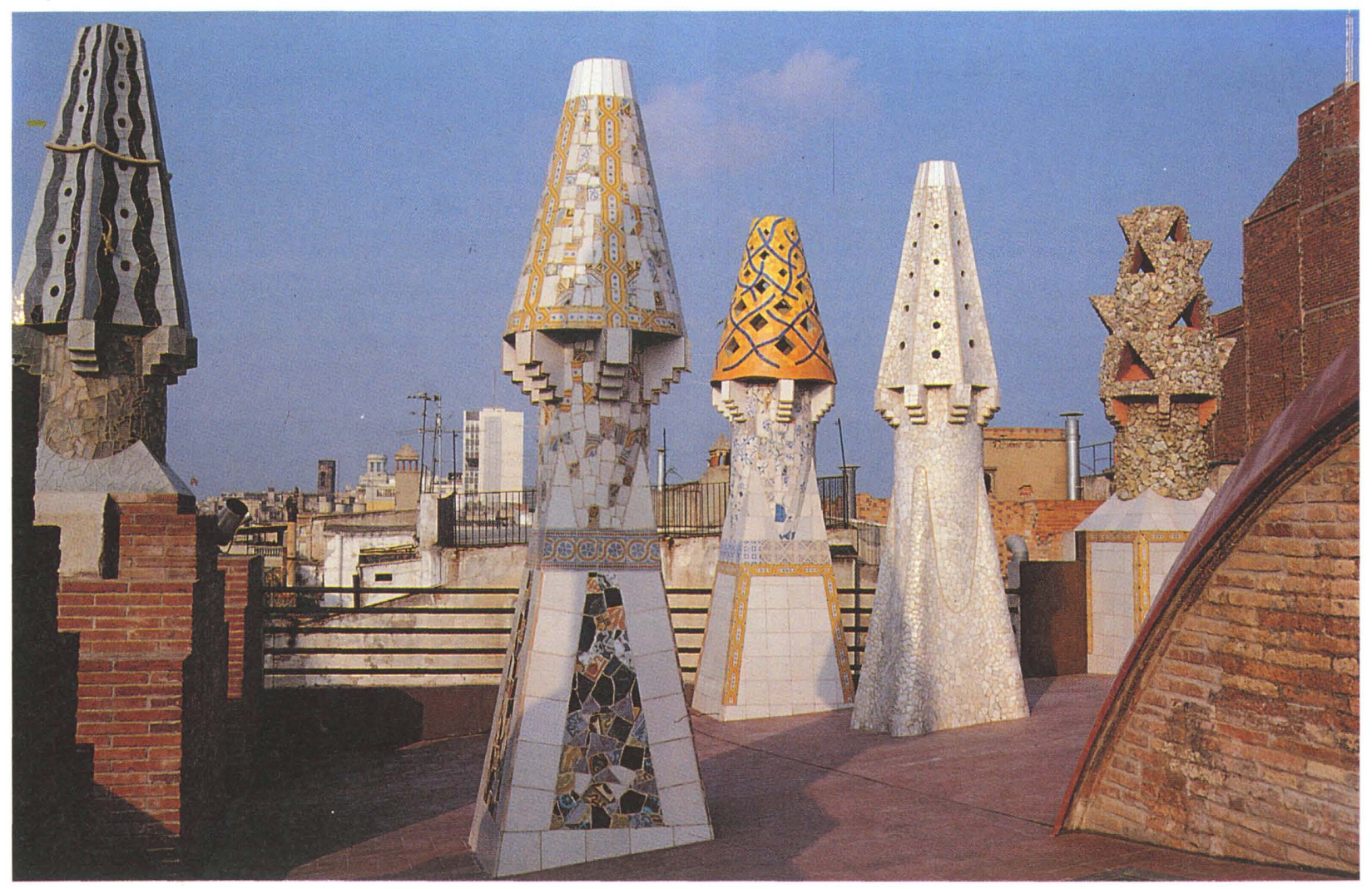




\section{Otros trabajos y estudios}

Como complemento de la restauración de las fachadas y de la cubierta se diseñó la iluminación eléctrica nocturna. El planteamiento fue terminante: no se trataba de competir en intensidad con la iluminación natural diurna, ni de hacer ostentación de ningún tipo (objetivos aparentes de muchas iluminaciones actuales, especialmente las promovidas por instituciones que confían en que el espectador asocie la capacidad de poder -económico, político o cultural-con la potencia lumínica que arrojan sobre sus edificios). Menos aún se trataba de alterar el carácter de la arquitectura (ese es el efecto, por ejemplo, de iluminarla con luz coloreada, vicio tan frecuente también hoy). Perseguíamos sólo dar énfasis a algunos elementos, sugerir otros, para crear un clima fantástico y sugestivo, propio y exclusivo de la contemplación nocturna de una arquitectura siempre hechicera.

En la fachada de mediodía, la luz blanca vertida sobre el pavimento crea ese clima irreal, mientras el umbráculo, a diferencia del papel que juega durante el día, arroja hacia el exterior una luz que toma el color de la madera que baña. En la azotea, unos focos concentrados iluminan la veleta y algunas caperuzas, no todas, mientras por los tragaluces y las ventanas de los edículos emerge una luz que,

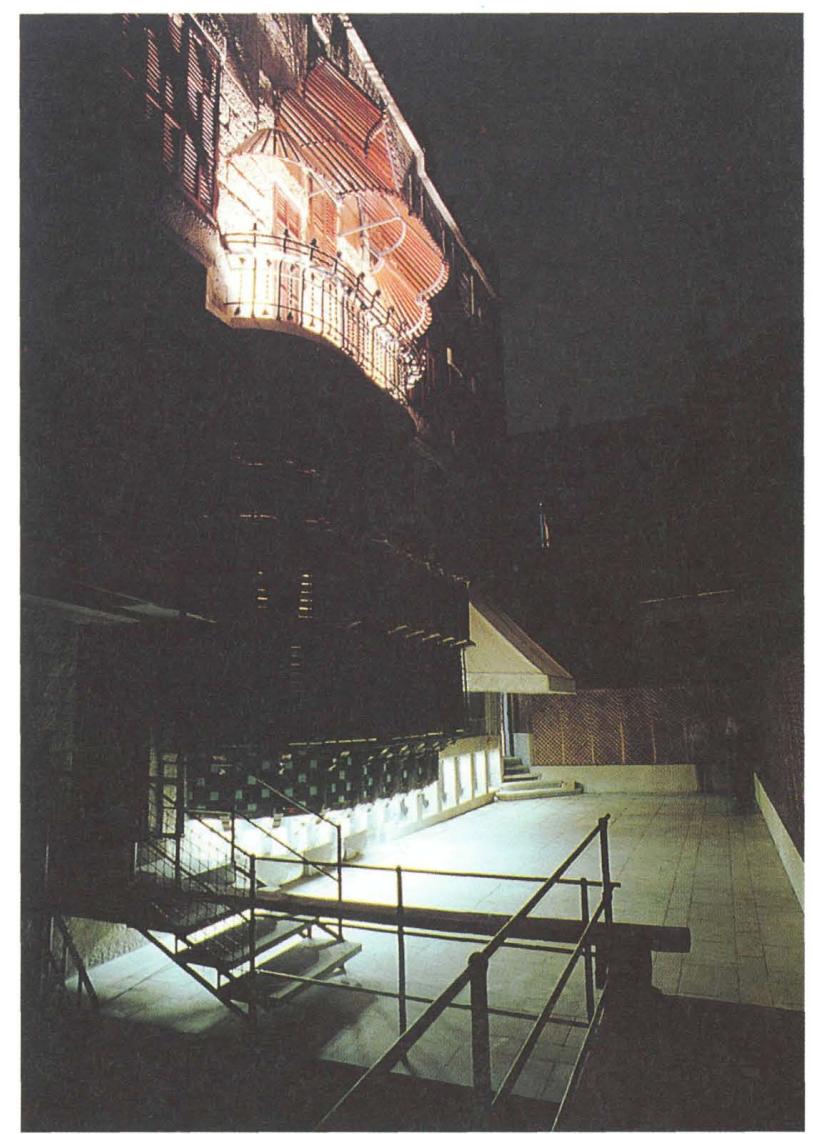

La iluminación artificial no pretende competir con la diurna, sino sugerir algunos puntos de vista y reforzar la atmósfera fantástica de la terraza y la azotea.

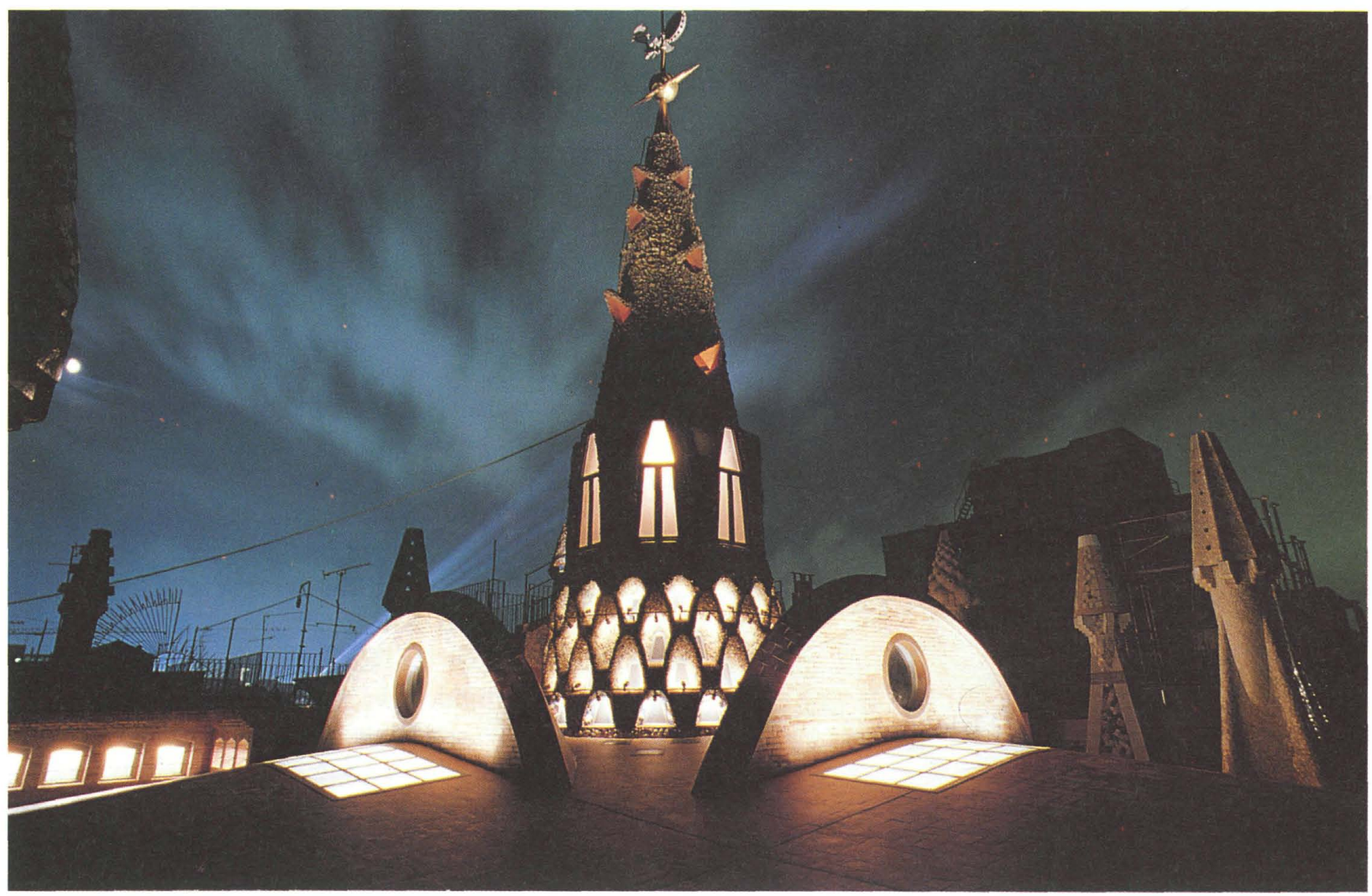

(c) Consejo Superior de Investigaciones Científicas 

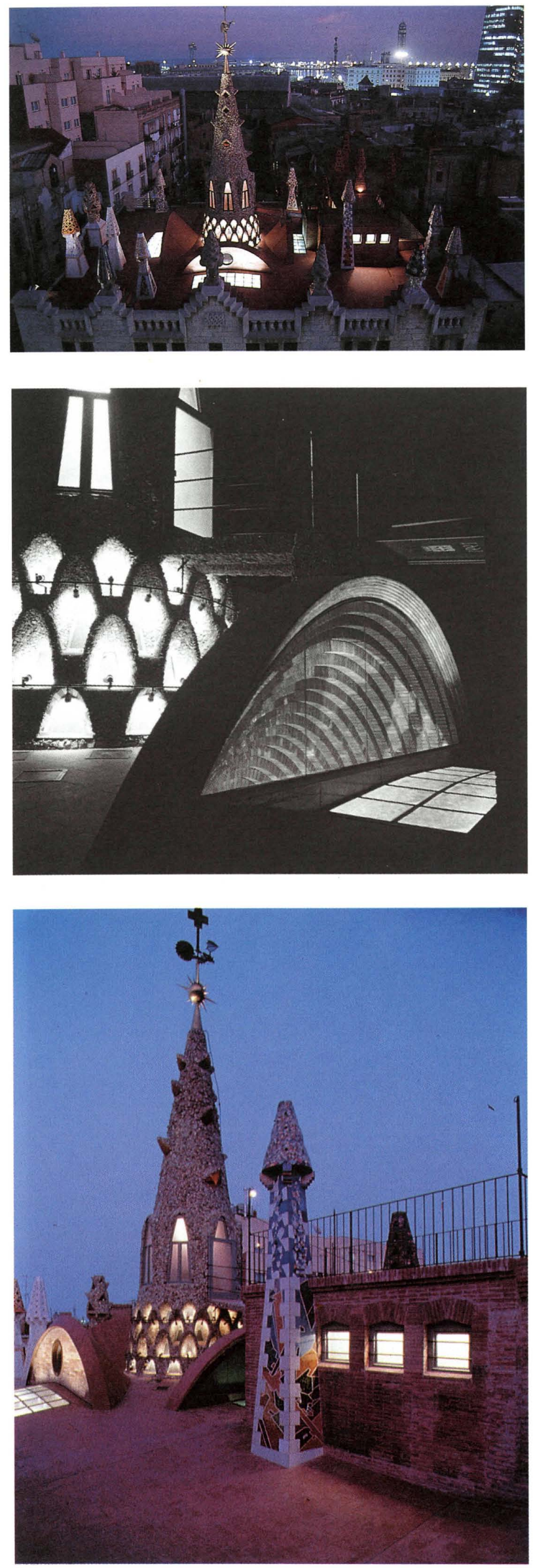

reflejada en el ladrillo descubierto de los lunetos y de las escaleras y en la cerámica del pavimento, parece envolver misteriosamente al sorprendido visitante.

También hemos estudiado ya algunos aspectos de la iluminación natural interior. A pesar de que las crónicas de la época de construcción del palacio elogien la luminosidad de su interior ("todos quedan sorprendidos al encontrarse en un recinto luminoso, cuando en vista del exterior presentían una morada oscura y sombría", dijo La Ilustración en 1891), el palacio tiene una bien ganada fama de oscuro. Una parte de los estudios que hemos realizado al margen o paralelos a las obras persiguen la recuperación de la luminosidad original o, incluso, mejorarla para acentuar o revalorizar aspectos espaciales del edificio.

Las obras de la azotea fueron aprovechadas en este sentido. Al desembarazar el luneto del sudoeste se produjo un hecho insólito. Por primera vez los rayos solares inundaron el salón central e incluso acariciaron el busto del señor Güell que se halla al pie de la escalera. Fue el 3 de abril de 1991. Tuvimos la tentación de perpetuar aquel efecto. Sin embargo, la inquietante sensación de falta de estabilidad de la cúpula que produce una entrada de luz marcadamente asimétrica nos aconsejó equilibrarla de nuevo en los cuatro lunetos, lo que obliga a tamizar la luz que entra por el luneto recién abierto.

De momento se ha dispuesto un cerramiento provisional de madera mientras estudiamos cómo utilizar para matizar la luz tanto las bellas vidrieras malogradas (que han sido colocadas ya de acuerdo con nuestro anteproyecto de reordenación de ese espacio), como el nuevo órgano que ha de instalarse bajo ese luneto, en el lugar que ocupó el antiguo, pero sin entrar en conflicto ahora con la azotea, del que el organero Gerhard Grenzing, con la colaboración del arquitecto Simon Platt, ha esbozado ya un primer estudio.

Por último, he de citar la recuperación del mobiliario original. La Diputación de Barcelona recibió el palacio sin apenas muebles, ya que la familia Güell se los había repartido. Cuando se instaló el Instituto del Teatro, dirigido a la sazón por el catedrático y escritor Guillermo Díaz-Plaja, y también en algún momento posterior, se adquirieron muebles de época para decorar el palacio, algunos de buena calidad. Se trataba, no obstante, de muebles modernistas que bien poco tenían que ver con la decoración 
primitiva de un edificio construido antes de la eclosión del Modernisme.

La recuperación ambiental que perseguimos en la restauración nos exigía devolver al palacio, en lo posible, aquellos muebles primigenios. Raquel Lacuesta, incansable en sus investigaciones, halló la pista de una parte esencial de ese mobiliario, el comedor completo y otras piezas de la planta noble. Los utilizaban los marqueses de Sant Mori en el castillo de esa localidad ampurdanesa.

Estudios de iluminación natural y de revalorización de espacios.
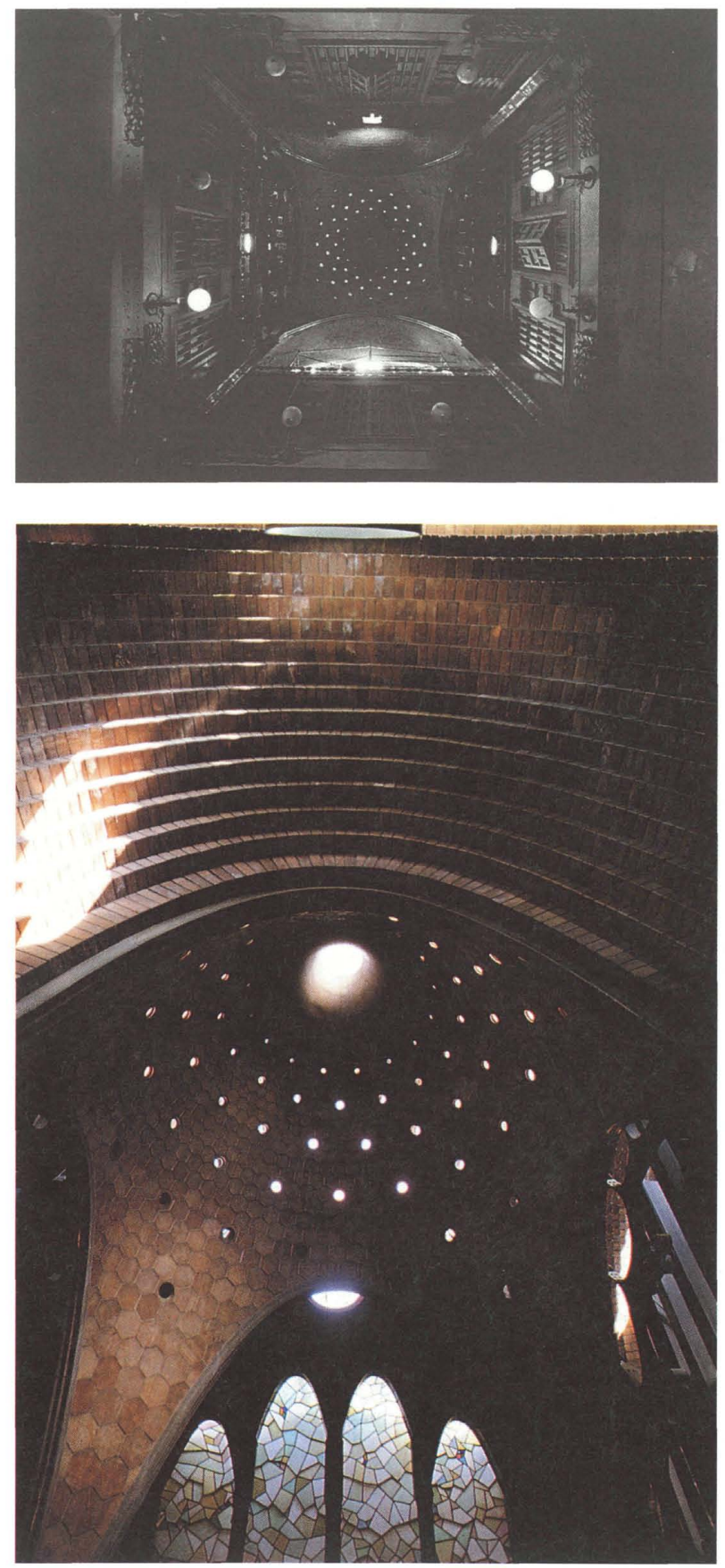

Pudimos convencer a nuestros superiores de la importancia del hallazgo y conseguimos los recursos económicos para adquirir las piezas. Hoy se encuentran de nuevo en su primer destino.

Esto han dado de sí los diez primeros años del proceso metodológico y crítico de conservación del Palau Güell. Falta por completar la actuación en la planta baja (restaurar la antigua cochera y acondicionar otras dependencias, trabajos iniciados en 1993), restaurar la planta subterránea (el atractivo paisaje de pilares y bóvedas de obra vista), limpiar y acondicionar para la visita y el uso representativo la planta noble, el entresuelo y la planta de dormitorios, recuperar el altar de la capilla que se perdió cuando la guerra civil, acabar de recuperar el mobiliario (se negocia ahora que vuelvan al palacio los muebles depositados en el Museu Gaudí), acondicionar para actos y reuniones la planta desván, adecentar la escalera de servicio, renovar la instalación eléctrica de las plantas (sólo se han renovado las líneas generales), sustituir el ascensor, e instalar el nuevo órgano que permita recuperar el palacio como auditorio de excepción.

La vuelta de una parte del mobiliario original del palacio ba sido un paso muy importante para que el palacio recupere su ambiente, un aspecto que no puede olvidar la restauración.

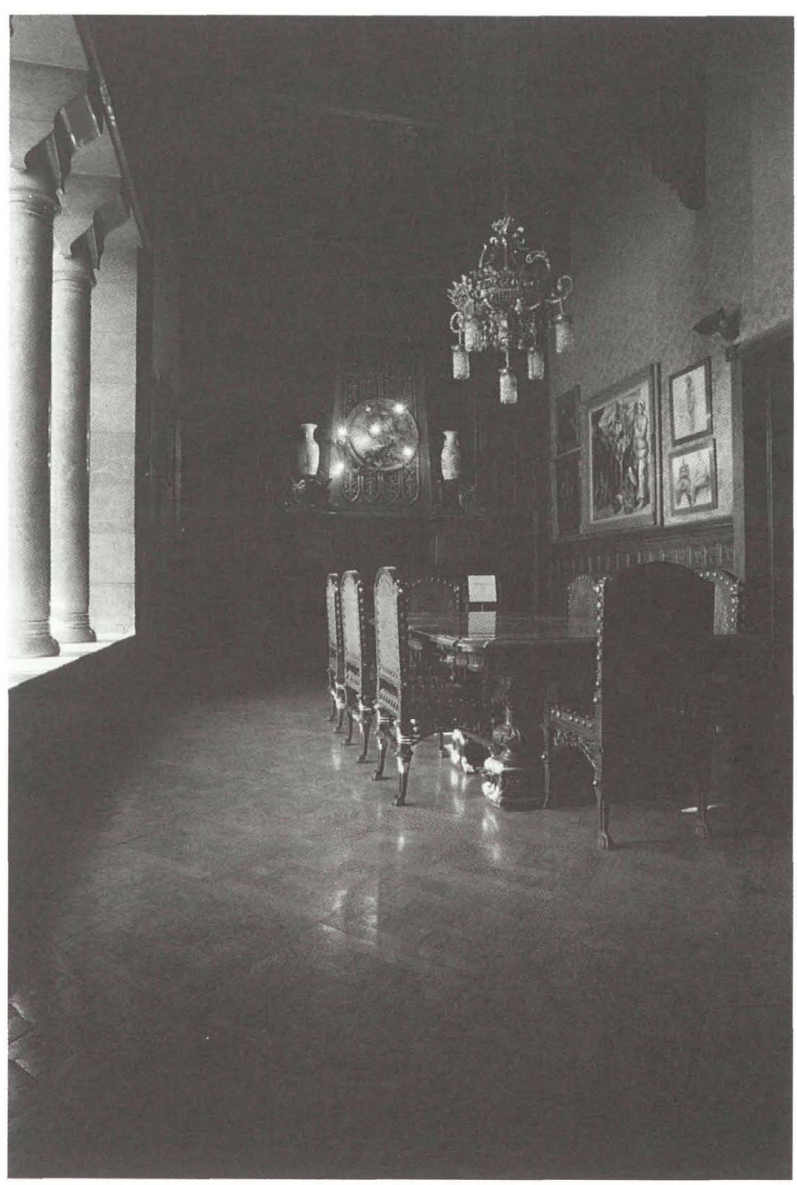




\section{BIBLIOGRAFIA}

César Martinell; Gaudí, su vida, su teoría, su obra, Barcelona, 1967.

Antoni González; 32 monuments catalans, Diputació de Barcelona, 1986.

P. Carbó, R. Lacuesta, J.M. Moreno; "Palau Güell de Barcelona", Memòria 1984 del servei de Catalogació i Conservació de Monuments, Diputació de Barcelona, 1986.

J. de Puig y otros; El Palau Güell, Diputació de Barcelona, 1990.

Antoni González, Pablo Carbó, Carles Buxadé, Joan Margarit, Josep María Moreno; "Gaudí, constructor", Informes de la construcción, Instituto Eduardo Torroja, núm. 408, Madrid, julio-agosto de 1990.
A. Gonzalez, R. Lacuesta, J. de Puig; El Palacio Güell. Guía, Diputació de Barcelona, julio de 1992.

Antoni Gonzalez, Josep María Moreno; "II restauro del Palazzo Güell di Barcellona", en Maria Giuseppina Gimma (ed.), II restauro dell'architettura moderna, Aniasper / BetaGamma editrice, Viterbo, 1993.

Raquel Lacuesta, Antoni González, Giorgio Croci, Domingo García-Pozuelos; "El Palau Güell de Barcelona", en Quaderns Cientifics $i$ Técnics, n. 5, Diputació de Barcelona, noviembre de 1993.

Antoni González, "Originalità ed autenticità nel restauro di palazzo Güell", en Parametro, nº 197, Bolonia, agosto de 1993.

Raquel ,Lacuesta, "I Camini di Palazzo Güell. Una metodología per il restauro", en Parametro, nำ 197, Bolonia, agosto de 1993.
1. Robert Hughes, Barcelona, Ed. Anagrama, Barcelona, 1992.

2. El Palau Güell fue el primer edificio moderno que se incluyó en la lista del Patrimonio Mundial de la UNESCO. Ocurrió en 1985. El palacio había sido declarado monumento histórico-artístico de interés nacional en 1969, veinte años antes de llegar a centenario, y fue también el primer caso en que esto ocurría.

3. Citado en Joan Bergós Massó, Gaudi, l’home i l'obra, Editorial Aymà, Barcelona, 1953.
4. Leopoldo Torres Balbás, "Diario de obras en la Alhambra", en Cuadernos de la Alhambra, núm. 1, Granada, 1965.

5. Véase Antoni González Moreno-Navarro, "Restaurar monumentos, una metodología específica", en Informes de la construcción, Instituto Eduardo Torroja, núm. 397, Madrid, septiembreoctubre de 1988

6. Revista Hispano-Americana La Ilustración, Barcelona, enerofebrero de 1891

\section{Ficha técnica}

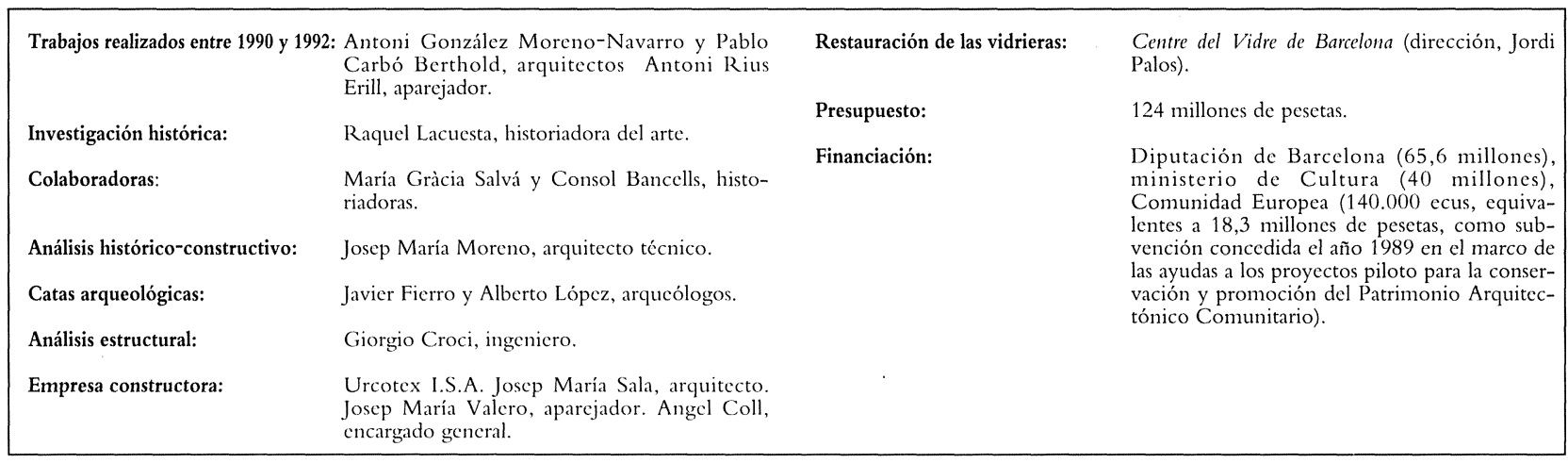

